\title{
Greening Logistics Implementation of Green Logistics Practices Through Interaction
}

\author{
Niklas Simm
}



Linkoping studies in science and technology.

Licentiate Thesis No. 1909

\title{
Greening Logistics \\ Implementing Green Logistics Practices \\ Through Interaction
}

\author{
Niklas Simm
}

1.U UNNKERESGS

\author{
Logistics and Quality Management \\ Department of Management and Engineering, \\ Faculty of Science and Engineering \\ Linköping University, SE-581 83 Linköping, Sweden \\ Linköping 2021
}


(C) Niklas Simm, 2021

Greening Logistics: Implementing Green Logistics Practices Through Interaction

$(\mathrm{cc})$ EY-No License. To view a copy of this license, visit

http://creativecommons.org/licenses/by-nc/4.0/.

Linköping Studies in Science and Technology, Licentiate Thesis No. 1909

ISSN: 0280-7971

ISBN: 978-91-7929-626-1

Printed in Sweden by LiU-Tryck, 2021

Distributed by:

Linköping University

Department of Management and Engineering

SE-581 83 Linköping, Sweden

Tel.: +4613281000 


\section{Abstract}

The greening of our logistics systems has become a concern for many more than just those that operate and find themselves within supply chains. One of the organizations that accounts for a large share of negative environmental impact is the logistics service providers (LSPs), often responsible for the management and operation of transports. However, LSPs cannot be held solely accountable, as their services are procured from shippers in need of shipping goods to their customers. Additionally, many shippers affect the environmental performance of the logistics systems, both with their own operations and what they request from LSPs but also their promises to customers. By interacting with each other, organizations can share resources, information, and knowledge, as these items are required for implementing green logistics practices (GLPs). With additional resources, information, and knowledge, LSPs can implement GLPs successfully, without needing to procure or acquire resources, information, or knowledge, elsewhere. Therefore, the purpose of this licentiate thesis is to explore how supply chain interaction can facilitate logistics service providers to implement green logistics practices.

The research in this thesis is both explorative and descriptive. The purpose is explorative, but to fulfill the purpose, GLPs must be described to include the need for interaction. Building on the description of GLPs is the exploration of forms of interactions that occur when implementing GLPs. Lastly, the interactions are explored throughout the implementation process to investigate how the interactions are characterized in the different phases that constitute the implementation process. Throughout the analysis and discussion, several important organizations for the LSP to interact with are identified; this includes shippers, technology providers, as well as actors within the LSPs. Different forms of interaction, which includes both internal and external interaction with different organizations and actors, are suggested in order for LSPs to acquire the information, resources, and knowledge necessary to implement GLPs. Additionally, the forms of interactions between organizations and actors changed with the implementation process, which suggests that different phases characterize both the interactions that occur and the need for interaction. Finally, it is proposed that supply chain interaction facilitates the LSPs to implement GLPs, by allowing the LSP to acquire information, knowledge, and resources through communication, trust, and commitment with other organizations or actors.

The main contribution of this licentiate thesis to research and the green logistics literature is the identification of the need to have various forms of interaction with different organizations and actors when implementing GLPs. This illustrates that other organizations than the shipper can have information, resources, or knowledge that can facilitate LSPs to implement GLPs, instead of the LSP acquiring similar information, resources, or knowledge elsewhere and by themselves. Additionally, as interaction is a "two-way street", it allows access to valuable items and requires items offered in exchange for those items. Therefore, it is suggested to have various forms of external interaction with other organizations or internal interaction with actors within the same organizations. Thus, the interactions become less costly to withhold, and as the purpose of the interaction is to mitigate the cost of implementing GLPs, the finalized cost of implementing GLPs becomes lower. The contribution to practice instead helps organizations to highlight that interaction with key organizations can facilitate the implantation of GLPs and thus facilitate the much-required greening of our logistics systems. 



\section{Sammanfattning}

Att göra våra logistiksystem grönare, har blivit en angelägenhet för fler än de som befinner sig och verkar i försörjningskedjorna. En typ av organisation som står för en stor del av den negativa påverkan som logistiken ger upphov till är logistiktjänsteleverantörer (LSPs), vilka ansvarar för och utför merparten av transporterna i logistiksystemen. Däremot kan inte enbart LSPs hållas ansvariga för utsläpp och den negativa miljöpåverkan som uppstår i logistiksystemet, eftersom deras tjänster upphandlas av varuägare, som behöver få ut gods till sina kunder. Dessutom påverkar många varuägare miljöprestandan i logistiksystemen genom sina egna handlingar men också genom vad de begär och kräver av LSPs samt utlovar till sina kunder. Genom interaktion, kan organisationer dela resurser, information, och kunskap, som krävs för att implementera gröna logistiklösningar (GLPs). Med ytterligare resurser, information och kunskap kan LSPs implementera GLPs framgångsrikt, utan att behöva förskaffa eller köpa resurser, information eller kunskap på annat håll. Därför är syftet i den här licentiatavhandlingen att utforska hur interaktion kan främja LSP att implementera GLPs.

Forskningen i den här licentiatavhandlingen är både explorativ och deskriptiv. Syftet är explorativt, men för att kunna uppnå syftet, måste GLPs beskrivas på ett sätt så de innefattar interaktion. Baserad på den beskrivningen, kan former av interaktion som uppstår när GLPs implementeras utforskas. Slutligen så utforskas interaktionerna genom implementeringsprocessen, för att undersöka hur interaktionerna som uppstår karaktäriseras i olika faser som utgör implementeringsprocessen. I analysen identifieras flera viktiga organisationer för LSP att interagera med när GLP implementeras. Dessa är varuägare, teknikleverantörer samt interna aktörer inom LSP. Olika former av interaktion, vilket inkluderar både extern och intern interaktion föreslås som nödvändigt för att tillgodogöra sig information, resurser, och kunskap som behövs för att implementera GLPs. Dessutom, förekom det att formerna av interaktionerna kunde ändras genom implementeringsprocessen, vilket föreslår att interaktionsbehovet förändras genom olika faser. Slutligen, föreslås det att interaktion kan främja LSPs att implementera GLPs genom att tillåta LSP att skaffa resurser, information, och kunskap genom kommunikation, tillit, och engagemang till andra organisationer eller aktörer.

Licentiatavhandlingens huvudsakliga bidrag till forskning och den gröna logistiklitteraturen är identifieringen av behovet att ha olika former av interaktion med olika organisationer och aktörer när GLPs implementeras. Detta illustrerar att andra organisationer än varuägare kan ha information, resurser, eller kunskap som behövs för att LSPs ska kunna implementera GLPs, istället för att LSP ska skaffa liknande resurser på egen hand. Dessutom, eftersom interaktion sker mellan två parter och i två riktningar, så ger det möjligheten att få tillgång till värdefulla föremål (ex. information eller resurser), men det kräver också att det skjuts in föremål. Därför föreslås det att man bör ha olika former av interaktion, eftersom det gör att interaktionerna blir mindre krävande att upprätthålla. Eftersom syftet är att främja LSP att implementera GLPs, så blir den slutliga kostnaden för att implementera GLPs lägre, om interaktionerna är så effektiva som möjligt i termer av resurser, information, eller kunskap som läggs in i interaktionerna. Bidraget till praktiker är istället att interaktion kan hjälpa organisationer inse att interaktion kan möjliggöra implementeringen av GLPs, eftersom det tillåter organisationer att skaffa resurser, information, och kunskap som krävs för att implementera GLPs. 



\section{Acknowledgements}

Here it is. Here it actually is. The process of writing this thesis have been a rollercoaster of emotions. I say that, because one of the biggest outtakes from this process, is that I am a social person. I am a social person that needs to interact with other people, both to function as human but also to perform in terms of research and work. Perhaps this was an insight from studying interactions, but also a lesson learned from the full-blown pandemic which greatly hindered the possibilities of interacting. However, interaction has also been the main source of inspiration for this thesis, through interaction with other researchers, colleagues, and friends. Without interaction, this licentiate thesis would not have been possible - it is after all, in the title of the thesis.

In retrospect, the advantages of being on a rollercoaster is that each climb, no matter how steep or long, will be followed by decline which will help in the following climb. For me, many of the climbs have been tough, but here we are, at the end of the rollercoaster, with a feeling of accomplishment and an overall cheerful experience. But the best part with rollercoasters, is that the experience is shared with other people, and so has this process. There is a list of people who made this licentiate thesis possible, and here comes my best effort of acknowledging them.

First, I would like to extend the sincerest gratitude and thank you to my supervisors Maria Björklund and Uni Sallnäs. Without your encouragement, feedback, discussions, and guidance, this thesis would not have been achievable. Thank you for pushing me, but to always make sure of my well-being. You are both incredible inspirations, and I have learned so tremendously much from the both of you. Thank you for allowing me to have two awesome supervisors, and for helping me become a better researcher. And especially thank you for helping me figure out how and when I perform optimally.

Of course, I would also want to thank all my colleagues for every fika-session and for the opendoor policies with possibilities of asking questions or having discussions, whether it concerns research or any of the other numerous interests of the people on our amazing workplace. We have an amazing culture, and I am grateful to be a part of such an amazing division. Thank you all, for making it easy to go to work. This goes without saying, but I would like to extend a special thank you to all the fellow doctoral students, whose processes somewhat overlaps or have overlapped with my own process. I see you all as mentors, and in fear of forgetting anyone, "you know who you are". I am looking forward to many more of our lunches in the "VIP".

Lastly, I would like to extend a big thank you to my family. Thank you for the support, and for everything you have done for me. A special thank you and apology to my mother, who have had to withstand discussions on logistics and business management at numerous holidays and family gatherings. To my father, who have inspired me into perusing the field of logistics and enabled me to acquire invaluable experience of practicing logistics management. To my brother, for allowing me to take my mind of research and instead onto handball and the numerous attempts of selling me on golf. Finally, to Sara, who I know will always be my biggest supporter, no matter what. Thank you.

Niklas Simm

Norrköping, May, 2021 



\section{Table of content}

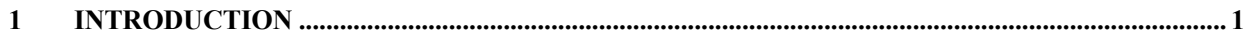

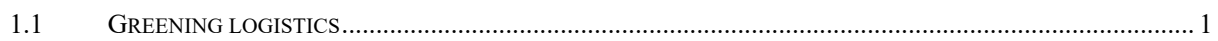

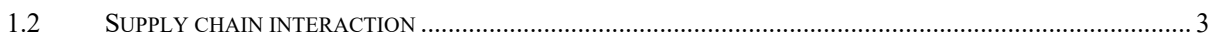

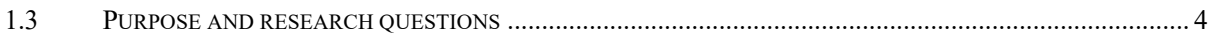

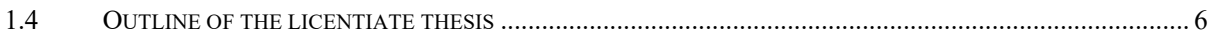

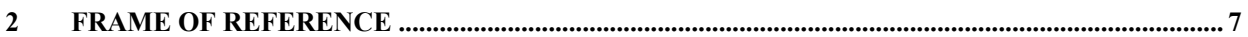

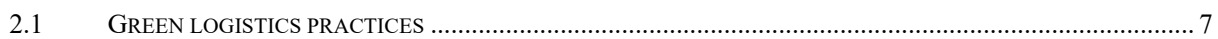

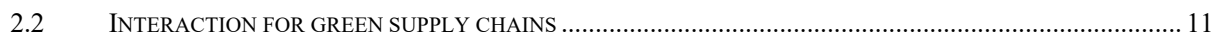

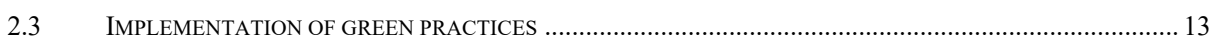

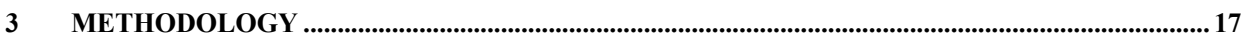

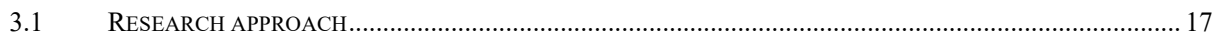

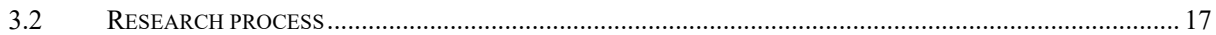

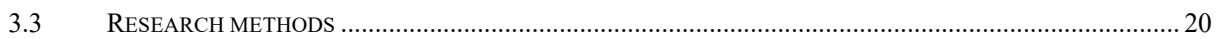

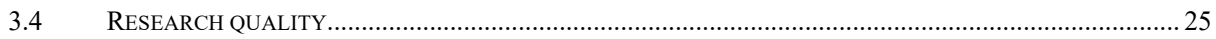

$4 \quad$ APPENDED PAPERS ......................................................................................................................... 27

4.1 PAPER I - INTER-ORGANIZATIONAL SUPPLY CHAIN INTERACTION FOR SUSTAINABILITY ......................22

4.2 PAPER II - Roles And Perspectives When Estimating Energy And EnVironmental

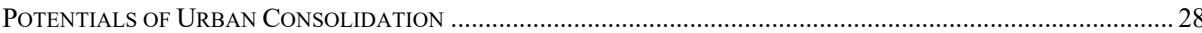

4.3 PAPER III - INTERACTION FOR SUCCESSFUl IMPLEMENTATION OF CLIMATE SMART Freight

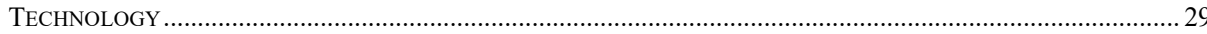

4.4 Case Report - Becoming Greener Together: A Study of A ShipPer AND AN LSP's

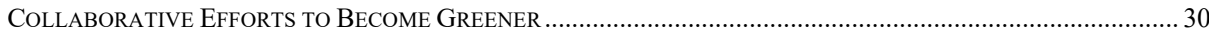

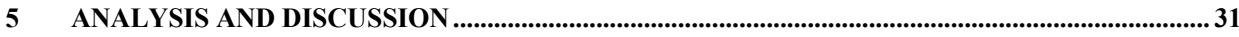

5.1 DESCRIBING GREEN LOGISTICS PRACTICES TO INCLUDE THE NEED FOR INTERACTION....................... 31

5.2 WHAT FORMS OF INTERACTIONS OCCUR IN THE IMPLEMENTATION OF GLPS ................................... 38

5.3 THE CHARACTERISTICS OF INTERACTION IN DIFFERENT PHASES OF IMPLEMENTING GLPS................. 45

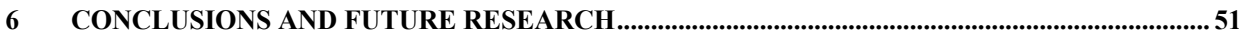

6.1 ANSWERING RESEARCH QUESTIONS AND PURPOSE ...................................................................... 51

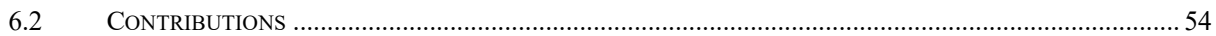

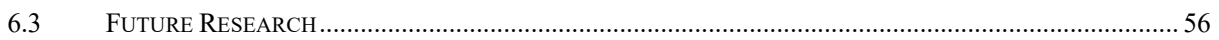

\section{REFERENCES}

APPENDED PAPERS 



\section{List of figures}

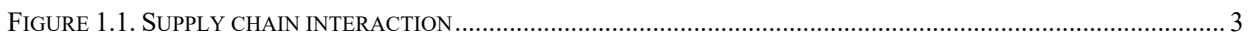

FIGURE 1.2. PERSPECTIVE OF RESEARCH QUESTIONS AND PURPOSE......................................................................... 6

FIGURE 2.1. ILLUSTRATION OF INTERACTION AS A CONTINUOUS RANGE WITH EXTREMES......................................11

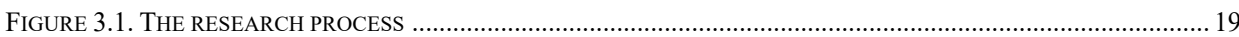

FIGURE 5.2 INTERACTION TO IMPLEMENT ALTERNATIVE FUEL, FROM PAPER III ..................................................... 39

FIGURE 5.3 INTERACTION TO IMPLEMENT A MUNICIPAL CONSOLIDATION CENTER, FROM PAPER II.......................... 40

FIGURE 5.4 INTERACTION TO COLLABORATIVELY IDENTIFY GLPS, FROM CASE REPORT ....................................... 41

\section{List of tables}

TABLE 2.1. TRANSPORT-RELATED GREEN LOGISTICS PRACTICES FROM THE LITERATURE ……................................. 8

TABLE 2.2. IMPLEMENTATION OF GREEN LOGISTICS PRACTICES ADAPTED FROM LITERATURE ................................. 14

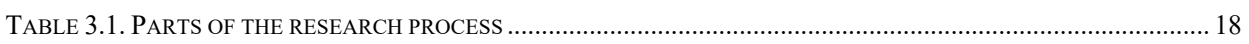

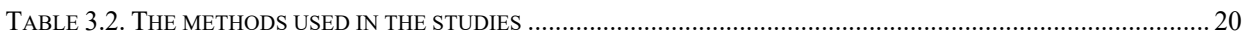

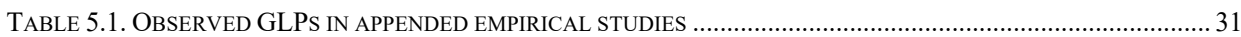

TABLE 5.2. THE PHASES FOUND IN THE LITERATURE ON WHICH THE EMPIRICAL STUDIES FOCUS ............................ 46

TABLE 5.3. SUMMARY ON HOW THE PHASES CHARACTERIZE THE INTERACTIONS WHEN IMPLEMENTING GLPS ..... 49 



\section{List of appended papers}

\section{Paper I}

Ülgen, V.S., Björklund, M., Simm, N. \& Forslund, H. (2019). "Inter-organizational supply chain interaction for sustainability: A systematic literature review", Sustainability, 11, 5488.

\section{Paper II}

Björklund, M. \& Simm, N. (2019). "Roles and Perspectives When Estimating Energy and Environmental Potentials of Urban Consolidation”, Energies, 12, 4811.

\section{Paper III}

Simm, N. \& Björklund, M. (2020). "Interaction for Successful Implementation of Climate Smart Freight Technology”, NoFoMa 2020, 17-18 September, Reykjavik, Iceland (Distance).

\section{Case report}

Simm, N. (2020). "Becoming Greener Together: A Study of a Shipper and an LSP's Collaborative Efforts to Become Greener", Case Report, Unpublished.

\section{Contribution in the appended papers}

\section{Paper I}

The author of this thesis joined the process as the paper was advanced from a conference paper toward a journal paper. The author of this thesis took part in the collective reading and coding of the papers included in the literature review as additional papers were added to the review. Additionally, the author of this thesis visualized the data based on the coding, participated in parts of the analysis, and supported the review process.

\section{Paper II}

The authors took equal responsibility for the frame of reference and the collection of empirical data. The author of this thesis conducted the internet scan, and contributed to the research design, analysis, and changes during the review process.

\section{Paper III}

The authors contributed equally with research ideas and research design. The author of this thesis took lead in the design of the introduction and frame of reference, and had the responsibility for the, analysis, and changes during the review process. Both researchers participated equally in the empirical data collection.

\section{Case report}

The author of this thesis is the sole author of the case report. 



\section{Introduction}

\subsection{Greening logistics}

It is widely known that freight transports and related logistical operations have negative effects on the environment (McKinnon, 2015a). With the growth of trends such as e-commerce and globalization, the required logistical services are increasing, accompanied by associated negative environmental effects such as pollution, climate change, and congestion (see e.g. Wu \& Dunn, 1995; Wolf \& Seuring, 2010). A quarter of the total $\mathrm{CO}_{2}$ emissions worldwide come from road transports (IEA, 2018), and despite declining curves in some geographical areas, the total estimated emissions from the transport sector are expected to rise (ibid.). By 2050, the demand for freight transports will have tripled (International Transport Forum, 2019). This requires the greening of logistics, where transports and logistics operations need to be made more environmentally friendly, both to cope with rising demand, and also to prevent climate change and pollution (McKinnon, 2015a).

For many years, environmental concerns have not been prioritized within logistics, despite the steady increase in research interest from academia in recent decades (see e.g. Evangelista et al., 2018; Brandenburg et al., 2019). The basic premise of logistics and its practices has been to manage and organize flows of goods in a resource-efficient manner, whilst simultaneously meeting the requirements of customers (Christopher, 2005). However, with the development of the UN's Global Goals for Sustainable Development and emerging environmental interest, logistics operators have acknowledged an increased public interest in environmental questions. For instance, worldwide logistics operator and service provider DHL has adopted a strategy with a mission "to reduce all logistics-related emissions to net zero by the year 2050" (DHL, 2020), and the Swedish branch of DB Schenker has set a target of "reducing emissions by 70\% before 2030" (DB Schenker, 2020). Similarly, large shippers such as H\&M state that "We are determined to play our part in tackling carbon emissions, and our goal is to become climate positive by 2040" (H\&M, 2020). This further highlight that, over the past decade, the growth in environmental concerns has changed the perception of logistics and added an additional dimension. This updated form of logistics, or green logistics, aims to manage and organize flows of goods in a resource-efficient manner and with consideration for the environment, that is, the greening of logistics without losing logistical efficiency (Wu \& Dunn, 1995).

Supply chain organizations have begun to take responsibility for their logistics practices, and have seen the need to consider the environmental effects of their practices (McKinnon, 2015a). Drivers behind this change in attitudes include opportunities to secure competitive advantages (Sarkis, 2003; Kumar et al., 2012), as well as preparing for consumer demands and inevitable regulatory pressures (see e.g. Liimatainen et al., 2015). Additionally, the personal motives of individuals within supply chain organizations can also act as drivers - a phenomenon referred to by the media and scholars as the "Greta Thunberg ${ }^{1}$ effect" - suggesting an overall increase in environmental concern. Depending on the supply chain position, different organizations can have different motives for engaging in green logistics (Murfield \& Tate, 2017), and as proposed

\footnotetext{
${ }^{1}$ Swedish environmental activist, known internationally for challenging world leaders to take immediate action against climate change despite her young age.
} 


\section{Introduction}

by e.g. Krause et al. (2009), the environmental performance of individual organizations depends on the overall performance of the supply chain they are a part of. As the greening of logistics typically consists of technology implementation or structural changes (Aronsson \& Huge-Brodin, 2006), the involvement of several supply chain organizations is required, in order to mutually increase resource pools and to share competencies between organizations (Kumar et al., 2012).

In today's supply chains, most logistics practices are managed and performed by logistics service providers (LSPs). In line with e.g. Berglund et al. (1999), LSPs are defined as the executors and managers of transport and warehousing activities in the supply chain. This gives them a central role in the greening of logistics, as the environmental performance of the supply chain relies on the performance of LSPs (Murfield \& Tate, 2017). Despite extensive research having been dedicated to the greening of LSPs, often from the perspective of buyers of logistics services (henceforth referred to as shippers), through the perspective of the LSPs, or with a dyadic focus on both shippers and LSPs (see e.g. Martinsen \& Huge-Brodin, 2014; Bask et al., 2018; Jazairy, 2020b), academia calls for more research on the LSP perspective. An additional focus on LSPs' interactions with key organizations and with important actors within these organizations is specifically called for (see e.g. Evangelista et al., 2018). As LSPs become increasingly important for the environmental performance of supply chains, to become greener, they must be able to understand which external organizations to include and interact with during the implementation of green logistics practices.

\subsubsection{Implementing green logistic practices}

In order for LSPs to become greener, they must perform their logistics practices in a greener way or implement new green logistics practices (GLPs) (González-Benito \& González-Benito, 2006). Implementing GLPs can be achieved by implementing innovations, changing the structure of current logistics operations, or a combination of both (see e.g. Flint et al., 2005). Understanding the process of implementing such GLPs is important in order to understand the scope of such implementations and how these implementations can be facilitated. Within the field of logistics, and particularly green logistics, the exploration of different processes for such implementations has scarcely been investigated (see e.g. Wagner, 2008; Chu et al., 2019). The most established framework for implementing logistics innovation was presented by Flint et al. (2005), and works including green adaptations of this framework have not emerged until recently (see e.g. Björklund \& Forslund, 2018).

Regardless of the approach, implementing GLPs are assumed to not differ from implementing any other logistics practices, and similarly can be seen as some sort of process where activities are spread out across different phases over time (Busse \& Marcus Wallenburg, 2011; da Mota Pedrosa et al., 2015). The first phase concerns either an evaluation of current practice or some sort of acknowledgement of disturbances, drivers, or pressures to change (Flint et al., 2005; da Mota Pedrosa et al., 2015). The last phase often includes performance measurement, or evaluation of the practice, to ensure that implementation was successful (Flint et al., 2005). In between the first and last phases, various intermediate phases are proposed (see e.g. Flint et al., 2005; da Mota Pedrosa et al., 2015). These phases typically concern aspects such as design and operationalization of practice (Björklund \& Forslund, 2018). Additionally, literature agrees on the inclusion of other supply chain organizations in the implementation process, e.g. customers, and interaction with these organizations (da Mota Pedrosa, 2012; Chu et al., 2019), but also 


\section{Introduction}

calls for investigations into how this interaction supports the implementation of green logistics practices throughout the different phases (see e.g. Centobelli et al., 2017).

In addition to the view of the implementation of GLPs as a process, with several phases and the inclusion of other supply chain organizations, implementing green logistics practices is also a versatile process. Implementing GLPs can be initiated either by the LSPs themselves, or in the interface between LSPs and shippers (see e.g. Colicchia et al., 2013; Martinsen \& Huge-Brodin, 2014). Depending on where the GLPs are initiated and implemented, different forms of interaction may be required as different supply chain organizations will be involved (Evangelista et al., 2018). For instance, GLPs that require the implementation of new technology ought to include organizations that provide technology, and GLPs involved in the interface between shippers and LSPs ought to include both organizations. Additionally, Aronsson and Huge-Brodin (2006) conclude that GLPs have different impacts on organizational decision levels, e.g. strategic structural, tactical planning, and operational dayto-day, further highlighting the need to consider the effects of GLPs on other organizations and the requirement of different forms of interaction when implementing GLPs. This can be illustrated by DB Schenker, which states that its efforts to green logistics are carried out together with its customers, suppliers, and stakeholders (DB Schenker, 2020). Additional research on how other organizations should be included in the process of implementing (green) logistics practices is also called for (see e.g. da Mota Pedrosa et al., 2015).

\subsection{Supply chain interaction}

Organizations do not compete at individual level, but rather as the supply chain they are a part of (Christopher, 2005). In order for these supply chains to be successful, interaction between its organizations is considered a necessity (see e.g. Stank et al., 2001). Interaction is a reciprocal action between at least two parties and occurs either between organizations or within organizations. Intra-organizational interaction (i.e. internal interaction) is often referred to as a prerequisite for inter-organizational interaction (i.e. external interaction) (see e.g. Stank et al., 2001). Interaction also occurs both upstream and downstream in the supply chain (Flynn et al., 2010). In Figure 1.1 below, different directions and types of interaction are exemplified.

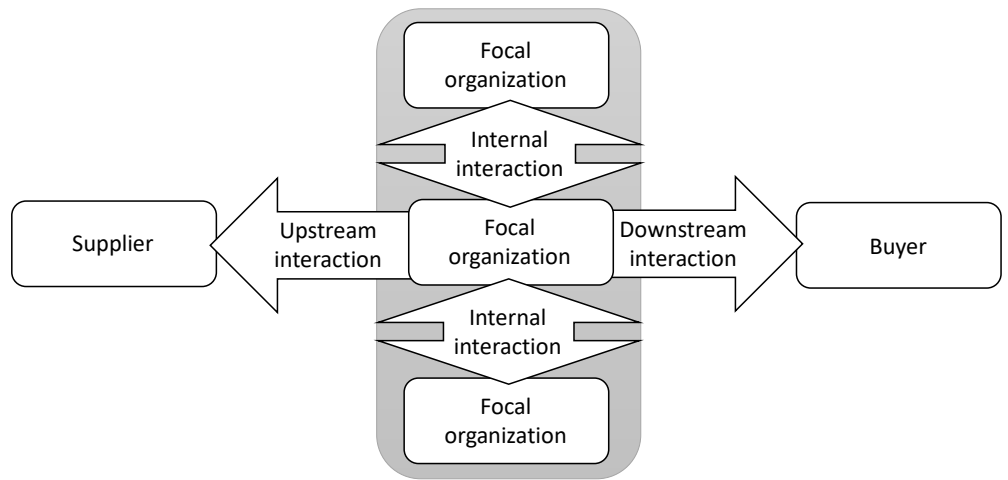

Figure 1.1. Supply chain interaction 


\section{Introduction}

The implementation of GLPs typically requires internal interaction in addition to external interaction, both with other supply chain organizations and with organizations outside the supply chain (Evangelista, 2014). To exemplify, Lammgård (2012) identified that shippers, LSPs, and different functions within the LSP had to interact to implement intermodal train services, providing examples of internal interaction and external interaction, whilst Anderhofstadt and Spinler (2019) found that LSPs consider both policies and legislations, and e.g. available refueling infrastructure when choosing green alternatives to fossil fuels, which illustrates external interaction.

In the literature, there is often a distinction between short-term, contracted, and price-focused interactions, i.e. arms-length interactions, and longer, joint, and service-focused interaction, i.e. collaboration (see e.g. Cooper \& Gardner, 1993; Soosay \& Hyland, 2015). The range of interactions can be described as a continuum, which suggests that an exact classification of interactions is difficult (Cooper \& Gardner, 1993). The form of interaction is commonly decided by the length of the commitment, availability on the market, market focus, dependency, information-sharing, communication, and investments (see e.g. Bowersox, 1992; Spekman et al., 1998; Soosay \& Hyland, 2015; Touboulic \& Walker, 2015), but the form can also be decided based on e.g. power dependencies or levels of trust (Soosay \& Hyland, 2015; Touboulic $\&$ Walker, 2015). In the green logistics literature, supply chain interaction - and in particular collaboration or deeper forms of interaction - is highlighted as a necessity in order to implement GLPs (see e.g. Carter \& Rogers, 2008).

\subsection{Purpose and research questions}

Previous research has highlighted the importance of including several organizations to achieve environmentally sustainable supply chains, often with a focus on the interaction between LSPs and shippers (see e.g. Touboulic \& Walker, 2015). However, little research has been dedicated to exploring how several other organizations also need to be included when LSPs implement GLPs into their operations (as proposed by e.g. Evangelista et al., 2018) and how these organizations can be included. This indicates that several organizations are affected and need to be included when LSPs become greener, but not in what way. One way to explore how organizations are and can be included is through the interactions that occur between LSPs and other organizations.

Interaction is suggested as a way for organizations to share resources such as financial means (e.g. sharing investments, as proposed by Bowersox (1992)), or information-sharing (see e.g. Spekman et al., 1998), which suggests that interaction can allow LSPs to gather e.g. additional resources in order to implement GLPs. It is often declared that interaction, and particularly collaboration (Touboulic \& Walker, 2015), is important, but not between which organizations and to what extent. This calls for a focus on which types of interaction occur between LSPs and other organizations when the GLPs are implemented throughout the implementation process. In light of the above reasoning, this thesis strives to explore how supply chain interaction between organizations can facilitate the implementation of green logistics practices. This leads to the purpose of the thesis, which is formulated as:

Explore how supply chain interaction can facilitate logistics service providers to implement green logistics practices. 


\section{Introduction}

To be able to fulfill the purpose of the study, three research questions are formulated and answered. As GLPs are an essential part of this thesis, they need to be investigated in order for the purpose to be fulfilled. There are many frameworks that present and describe GLPs, but not in a way that lays the foundation for interaction. By synthesizing established frameworks describing GLPs, this new framework can be used as a basis for an increased understanding of the effects GLPs can have on other organizations or actors and, by extension, whom should be interacted with and therefore included in the implementation of GLPs. The first research question thus addresses describing GLPs in such a way that they include how other actors (e.g. other organizations or functions within the organizations) will be required to participate and be included in the implementation of GLPs. Therefore, the first research question is formulated as:

Research question 1: How can green logistics practices be described to include the need for interaction?

Once GLPs have been described as entailing interaction, the interaction itself will be explored further. Interaction between and within organizations can take different forms and the form of interaction can be more or less collaborative, where closer forms of interaction should require more resources, but give greater benefits in return. Exploring the interactions that LSPs form to implement GLPs is pivotal in order to gain insights into which organizations can be included in the implementation of GLPs, and which organizations are not included. Additionally, by exploring what the interactions consists of and why they occur, insights into how other organizations are to be included are gained. These insights are important in order to understand how LSPs need to acquire and allocate resources, share information, and communicate in the interactions required to implement GLPs. The second research question will explore which interactions occur (e.g. between which organizations, or in which organizations) when implementing GLPs, but also what constitutes these interactions, and will thus ultimately explore the different forms of interaction that are required to implement different GLPs. The second research question is formulated as follows:

Research question 2: What forms of interactions can occur when implementing green logistics practices?

As the first research questions gives an increased understanding of implementing GLPs and how this concerns multiple organizations, the second research question explores interactions as a way of including other organizations. However, with an increased understanding of GLPs and interaction, there is also a need to understand how interaction is affected during the process of implementing GLPs, in order to understand how interaction can facilitate the implementation of GLPs throughout the entire implementation process. Typically, interaction is highlighted as a necessity to implement GLPs, but the implementation of GLPs progresses over time, and during the course of the implementation process interaction with other organizations may not always be a necessity, or even in a constant form. Understanding when and how to interact with other organizations can help LSPs to be resource efficient in their implementation processes. The interaction that is required for the implementation of GLPs differs with regard to the phase of the implementation process, as some phases can require more interaction, whilst other phases can require less, or even no interaction. Therefore, it is interesting to explore how the different interactions change in the different phases, and ultimately how the interactions can change during the course of the implementation process. Thus, the third research question is formulated as: 


\section{Introduction}

Research question 3: What characterizes the interactions that occur in the different phases of implementing green logistics practices?

The relationship between the research questions signifies that the research questions must be answered in sequence. First, GLPs must be investigated and described to include the need for interaction. Second, interactions between and within LSPs and other organizations are explored, and third, how the interactions change throughout the process of implementing GLPs is explored. Once the three research questions have been answered, the purpose - which explores how interaction can facilitate LSPs to implement GLPs - can be addressed and fulfilled. As such, one must first understand the final product, i.e. GLPs, before exploring the interactions that include other organizations and how these interactions change during the implementation process. This is illustrated in Figure 1.2, where the purpose encompasses GLPs, interaction, and the implementation of GLPs. The figure also illustrates that there is a process of implementing GLPs, and that this process requires interaction.

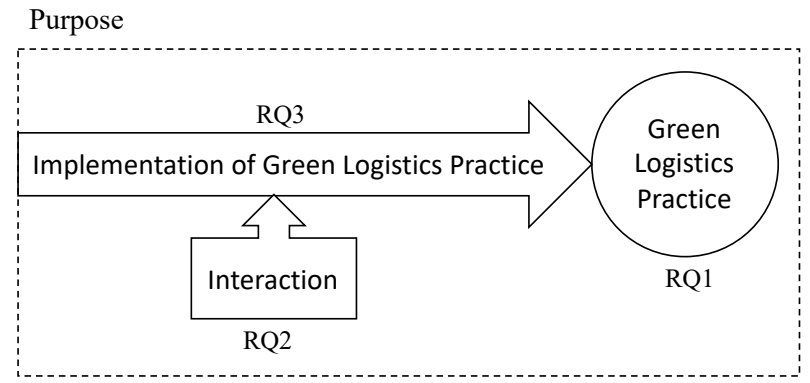

Figure 1.2. Perspective of research questions and purpose

\subsection{Outline of the licentiate thesis}

This thesis is a compilation thesis and consists of a thesis frame, three papers and one case report, which are appended in this licentiate thesis. The three papers consist of two journal articles and one conference paper. The case report is unpublished. The thesis frame is built upon the three papers and the case report but can be read comprehensibly without the appended papers and the case report. However, more detailed descriptions and results are found within the appended material. Additionally, summaries of the appended material are presented in chapter 4.

The structure of the thesis frame is as follows. After the introductory chapter (Chapter 1), the second chapter presents the frame of reference. The frame of reference consists of three sections, namely Green Logistics Practices, Interaction for Green Supply Chains, and Implementation of Green Practices. Following the frame of reference is a description of the methodology. This third chapter consists of four sections, which are Research Approach, Research Process, Research Methods, and Research Quality. A description of methods used in the appended material, and in the thesis frame, is presented in the Research Methods section. Chapter 4 presents the aforementioned summaries and contributions from the appended papers and the case report. The fifth chapter presents the analysis and discussion. The final chapter of the thesis frame (Chapter 6) contains the conclusions and contributions. Additionally, a full list of references, the papers, and the case report are appended at end of the thesis framework. 


\section{Frame of reference}

This chapter presents the frame of reference. It is structed in three sections. The first section presents green logistics practices, the second sections present interaction for green supply chains, and the third and final section presents implementation of green practices.

\subsection{Green logistics practices}

Green logistics practices (GLPs) are a well-researched area within the field of logistics (see e.g. Colicchia et al., 2013; Martinsen \& Huge-Brodin, 2014; Jazairy \& von Haartman, 2020). GLPs can be found within all fields of logistics, for instance transportation and warehousing, and are often grouped accordingly (Colicchia et al., 2013). Typically, GLPs are focused toward, but not limited to, transport, warehousing, procurement, and reverse logistics (see e.g. Wu \& Dunn, 1995; Björklund et al., 2016). Transports are often highlighted as the major driver of negative environmental impact within logistics (see e.g. Aronsson \& Huge-Brodin, 2006; McKinnon, 2015a), and in the literature it can be seen that it is more common to study and describe GLPs that target transport-related activities (Colicchia et al., 2013). In this thesis, the focus will be on GLPs that target reduced environmental impact from transports, which are further described below.

Despite earlier works that describe GLPs, no uniform generalized definition can be found in the literature (Perotti et al., 2012). Instead, it is common for different authors to choose a categorization to describe a set of gathered GLPs that is suitable for their purpose and with regard to their context or settings. Additionally, the characteristics of GLPs vary and can be studied and explained from different perspectives (Jazairy, 2020b), meaning that a standardized categorization or definition can be difficult. This is shown in Table 2.1, which lists a variety of GLPs identified within the literature that target reduced impact from transports.

As presented in Table 2.1, many GLPs appear in different frameworks and many authors use similar terminology for equivalent practices. Consequently, the number of actual practices presented in the literature is fewer than the number proposed. For instance, in Table 2.1, this can be exemplified by transport management, which in some literature includes city logistics projects such as urban consolidation centers (Martinsen \& Huge-Brodin, 2014), while other literature excludes city logistics projects and instead includes this in logistics systems design (Björklund et al., 2016). Regardless of the terminology used for GLPs that target city logistics, the purpose of such practices is to increase fill rates in transport, thus reducing the number of vehicles in a city logistics context. 
Table 2.1. Transport-related green logistics practices from the literature

\begin{tabular}{|c|c|}
\hline Reference & Transport-related green logistics practices \\
\hline McKinnon (2010) & $\begin{array}{l}\text { Reducing freight transport intensity; shifting freight to less } \\
\text { carbon-intensive transport modes; increasing vehicle utilization; } \\
\text { raising the energy efficiency of freight transport operations (e.g. } \\
\text { new vehicles or vehicle operation and maintenance); reducing } \\
\text { the carbon intensity of energy used in freight transport }\end{array}$ \\
\hline Perotti et al. (2012) & $\begin{array}{l}\text { (Re)design of logistics system components for higher } \\
\text { environmental efficiency; environmentally friendly facility } \\
\text { location; use of alternative fuels; mode selection based on "eco- } \\
\text { friendly" parameters; use of more recent/less polluting vehicles; } \\
\text { effective shipment consolidation and full vehicle loading; } \\
\text { routing systems to minimize travel distances; vehicle } \\
\text { maintenance and disposal }\end{array}$ \\
\hline Colicchia et al. (2013) & $\begin{array}{l}\text { Use of alternative fuels; use of more recent/less polluting } \\
\text { vehicles (e.g. electric, hybrid); vehicle speed reduction to save } \\
\text { fuel and reduce emissions; use of alternative transportation } \\
\text { modes (e.g. intermodal, combined); effective shipment } \\
\text { consolidation and full vehicle loading; routing systems to } \\
\text { minimize travel distances; (re)design of logistics system } \\
\text { components for greater environmental efficiency }\end{array}$ \\
\hline Martinsen \& Huge-Brodin (2014) & $\begin{array}{l}\text { Mode choice and intermodal transportation; logistics system } \\
\text { design; transport management; vehicle technology; behavioral } \\
\text { aspects (eco-driving); alternative fuels; environmental } \\
\text { management systems; choice of partners; emission data; other }\end{array}$ \\
\hline Björklund et al. (2016) & $\begin{array}{l}\text { Mode selection/intermodal transport; technical solutions; } \\
\text { transport supplier selection; eco-efficient driving; logistics } \\
\text { system design; transport management }\end{array}$ \\
\hline Jazairy (2020b) & $\begin{array}{l}\text { Green modal shifts; green transport management; green logistics } \\
\text { systems; green vehicle technologies; eco-driving; alternative } \\
\text { fuels }\end{array}$ \\
\hline
\end{tabular}

Within the scope of this thesis, a number of GLPs are proposed to capture the diversity of practices listed in Table 2.1. These GLPs are: eco-driving, increase fill rates in transports, alternative fuel, modal shift, logistic systems design, and vehicle technology. These six GLPs captures the essence of all the proposed GLPs in Table 2.1.

\section{Eco-driving}

Eco-driving is a collective term for actions taken to decrease environmental impact from transports while driving (Barkenbus, 2010). Often, eco-driving can be considered to only target vehicle speed (e.g. Colicchia et al., 2013), but is in fact broader. Operational actions, while driving, are typically adjusted and even speed, aiming for high gears, and to avoid idling and congestions, while decisions regarding e.g., type of vehicles, routing, maintenance are 


\section{Frame of reference}

considered as strategic or tactical decisions (Huang et al., 2018; Goes et al., 2020). Additionally, eco-driving can also include aspects such as load management and consideration to weather, but in line with e.g. Huang et al. (2018), in this thesis, eco-driving is considered as the choices and behavior of the drivers, also supported by e.g. labeling eco-driving as "behavioral aspects" (e.g. Martinsen \& Huge-Brodin, 2014). This includes, choice of routes, choice of vehicle, refueling and basic maintenance (e.g. tire pressure), and driving behavior. McKinnon (2010) mentions e.g., maintenance under ways to improve the energy efficiency of vehicles, which also agrees with being a choice of the driver.

The effects of eco-driving are often direct and achieved with low-cost investments, but effects can also be relatively large considering their simplicity (Goes et al., 2020). Effects gained from operational actions come from training, with or without continuous feedback to drivers, to further improve the behaviors and choices of drivers (Huang et al., 2018). Feedback can include in-vehicle devices to support drivers with behavioral choices through e.g. smartphones, dashboard-devices, or GPS (Huang et al., 2018), as well as systems to help with route optimization. Effects are often expressed as reduced fuel consumption and increased energy efficiency, but also contribute to increased road safety (Barkenbus, 2010; Goes et al., 2020).

\section{Increase fill rates in transports}

Increased fill rates in transports improve vehicle utilization and vehicle efficiency, which in turn improve the environmental performance of vehicles (e.g. reduced fuel consumption) (McKinnon, 2015b). Consolidation - or other forms of practices to increase fill rates in transports, thus aiming to reduce the number of transports - can vary in terms of design. Alternatives such as urban consolidation centers (UCCs) (see e.g. Allen et al., 2012; Björklund \& Johansson, 2018), measures taken by the shipper (Rogerson \& Santén, 2017), or planning and utilizing backhaul (Martinsen \& Huge-Brodin, 2014) are some examples of practices to increase fill rate in transports and reduce both the number of transports and empty running vehicles.

As exemplified, consolidation can occur on different levels (i.e. strategic, tactical, or operational) (see e.g. Aronsson \& Huge-Brodin, 2006; Rogerson \& Santén, 2017) and accordingly requires different resources. Additionally, different alternatives for consolidation require the involvement of either more or fewer supply chain organizations. As shown by Björklund et al. (2017), there are many organizations involved in initiating and operating UCCs, including organizations within the supply chain (e.g. shippers, receivers, and LSPs), as well as organizations outside the supply chain (e.g. authorities and residents). For other alternatives, such as those presented by Rogerson and Santén (2017), the organizations involved are often either the shipper (e.g. packaging and palletization) or the LSP (e.g. allocated capacity). Proposed environmental effects from consolidation include a reduction in the number of freight vehicles, increased environmental efficiency of vehicles (see e.g. Allen et al., 2012), and the opportunity to shift to alternative transport modes or fuel alternatives due to new transport frequencies and goods flows in order to further reduce the environmental impact (Aronsson \& Huge-Brodin, 2006; Johansson, 2020).

\section{Alternative fuels}

Alternative fuels include transitioning to more environmentally friendly fuel alternatives compared to fuels based on crude oil (e.g. petrol and diesel). Implementing new types of alternative fuels includes utilizing different types of vehicle technology (Björklund et al., 2016), either through the procurement of new vehicles (McKinnon, 2010), or through the use of alternative fuels for existing vehicles (see e.g. Perotti et al., 2012). Alternative fuels include 


\title{
2. Frame of reference
}

biofuels, gas, electricity, and hybrid fuel solutions (Leonardi et al., 2015; Anderhofstadt \& Spinler, 2019). This involves more or less polluting vehicles (Colicchia et al., 2013), as engine types limit possible alternative fuels. Different types of alternative fuels also offer varying effects on the reduction in emissions, and are more or less suitable for different modes of transport (Leonardi et al., 2015). Additionally, due to its dependency on technical innovations (e.g. vehicle technology and production of fuel), some alternatives have been developed further than others and are more attractive due to e.g. further developed refueling infrastructures (Anderhofstadt \& Spinler, 2019).

\begin{abstract}
Modal shift
Modal shift is a GLP that refers to the transfer of goods from transport modes with a higher negative environmental impact to more environmentally friendly transport modes (Eng-Larsson \& Kohn, 2012). Modal shifts include either conventional shifts between transport modes or the use of intermodal solutions where the loading unit or vehicle is unchanged (Eng-Larsson \& Kohn, 2012; Bask \& Rajahonka, 2017). This is similar to what Colicchia et al. (2013) refer to as the use of alternative transport modes. Often, modal shifts become a trade-off between environment and service, where the latter includes flexibility and lead times (see e.g. EngLarsson \& Norrman, 2014). In the literature, there is often a focus on the shift from road transports to either rail (Lammgård, 2012) or water (Rogerson et al., 2020), with or without intermodal solutions (Eng-Larsson \& Kohn, 2012; Lammgård, 2012). Typically, modal shifts involve both LSPs and shippers due to e.g. characteristics of loading units, customer service promises, or location of logistics facilities, which often concerns both types of organizations (Eng-Larsson \& Kohn, 2012; Bask \& Rajahonka, 2017).
\end{abstract}

\section{Logistics system design}

Naturally, the number of links and the length of these links will affect the environmental performance of a supply chain (Martinsen \& Huge-Brodin, 2014). Distinctions are made between a centralized logistics system and a decentralized logistics system. Centralization means reducing the number of nodes (e.g. warehouses or hubs), thus resulting in fewer but longer links with greater capacity, which allows for consolidation and thus gives effects similar to increased fill rates (see e.g. Aronsson \& Huge-Brodin, 2006), as presented above. Additional benefits of centralization are the possibility to hold larger product varieties, reducing supplementary deliveries when out of stock at decentralized locations, e.g. stores (Kohn \& Huge-Brodin, 2008). Alternatively, McKinnon (2010) refers to centralization as a mean to reduce the freight transport intensity, e.g. using fewer vehicles but with more capacity. Decentralization, by contrast, refers to the use of more nodes, creating more but shorter links in the system. This allows for more flexible distribution systems, with shorter distances between LSP and customers that require less transport work (Martinsen \& Huge-Brodin, 2014). Logistics system design involves either redesigning a current system (Colicchia et al., 2013) or designing a new logistics system with focus on green performance, e.g. a green logistics system (Jazairy, 2020b).

\section{Vehicle technology}

Vehicle technology is the collective term for different technologies that can be applied to vehicles, in order to reduce their environmental impact. McKinnon (2010) lists different measures such as low-resistance tires, aerodynamic profiling, and engine and exhaust technology. Additional types of vehicle technology include autonomous vehicles, IT-integrated vehicles, and intelligent idling control (see e.g. Jazairy, 2020b). Vehicle technology can to some extent be applicable to existing vehicles, as suggested by replacing the tires with low-friction tires (see e.g. Holmberg et al., 2014), or to the design of new vehicles (see e.g. Colicchia et al., 
2013). Vehicle technology often targets the tractors of vehicles, but technology can also target trailers, such as aerodynamic trailers and double-decked trailers (Madhusudhanan et al., 2021). Vehicle technology is also integrated within other GLPs in many ways, as exemplified by requiring new types of vehicle technology to utilize new types of fuel (Björklund et al., 2016), or instruments that help drivers to enhance the effects of eco-driving (Huang et al., 2018).

\title{
2.2 Interaction for green supply chains
}

Despite efforts in the literature, classifying distinct forms of interaction is complex due to the varied use of terminologies. Common expressions, e.g. cooperation, coordination, and collaboration, are used interchangeably for different purposes and different attributes are allocated with these terminologies. To exemplify, Bowersox (1992) links EDI with the term cooperation, whilst Spekman et al. (1998) suggest it is linked with coordination. Similarly, Cooper and Gardner (1993) use the term national account selling for a similar form of interaction to what Spekman et al. (1998) call coordination. Similar findings are present in the green logistics literature, where collaboration is seen as a collective term for all forms of closer interaction (e.g. coordination) (see e.g. Touboulic \& Walker, 2015).

In the literature, it is highlighted that more collaborative forms of interaction are a prerequisite for greening logistics (see e.g. Liimatainen et al., 2015; Evangelista et al., 2018). However, in their literature review, Soosay and Hyland (2015) found that the term collaboration is often overused and used interchangeably with any type of interaction. This further strengthens the claim regarding the complexity of defining distinct forms of interactions. Instead, one approach for classifying interactions is to describe the interaction in relation to the extremes, i.e. its position on a scale between arm's-length and collaboration. This is exemplified in Figure 2.1, where interactions can be either arm's-length or collaborative, or somewhere on a scale in between. Parameters for deciding which form of interaction occurs are suggested as intensity and formality of communication (e.g. Bowersox, 1992), sharing information and transferring knowledge (e.g. Spekman et al., 1998; Touboulic \& Walker, 2015), sharing resources and investing into the interaction itself (Bowersox, 1992; Soosay et al., 2008), and levels of trust and commitment (Touboulic \& Walker, 2015). In this thesis, the previously described classification will be applied and further developed below.

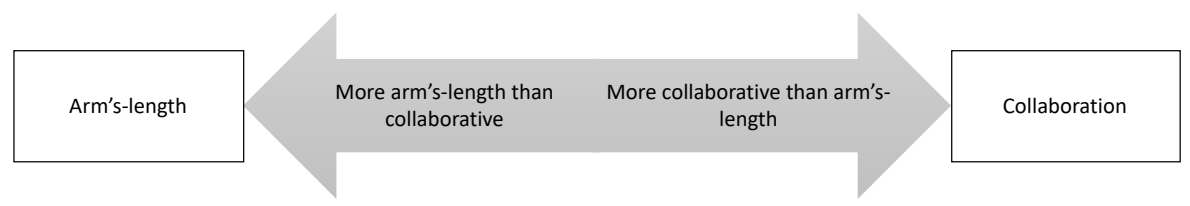

Figure 2.1. Illustration of interaction as a continuous range with extremes

\begin{abstract}
Arm's-length
Arm's-length interaction is uniformly suggested as the simplest form of interaction (see e.g. Cooper \& Gardner, 1993; Soosay \& Hyland, 2015). It relies on transactional exchanges with no or short contracts, minimal information exchange, and the purpose of minimizing the transaction cost of each purchase (Dyer \& Singh, 1998). In the green literature, it has been concluded both that LSP services are still purchased based on price and quality performance objectives (Wolf \& Seuring, 2010; Bask et al., 2018), and that short, price-focused and logistics service-focused contracts with LSPs hinder the improvement of environmental performance (see e.g. Piecyk \& Björklund, 2015; Jazairy, 2020a). This implies that arm's-length interactions are more common, despite calls for more collaborative approaches to make logistics greener.
\end{abstract}




\section{Frame of reference}

Often, the sole focus of arm's-length interactions is to achieve the lowest price possible with no dedicated resources or commitment in the interactions themselves (Bowersox, 1992). Arm'slength interaction is often the first engagement between two organizations, and will either have served its purpose after a given time and therefore be terminated (e.g. a contract or a single transaction) or it will evolve into a more collaborative form of interaction (Bowersox, 1992; Spekman et al., 1998). One way to evolve the interaction is to implement green initiatives, which increases the complexity in the supply chain (Murfield \& Tate, 2017). Most interactions only occur as arm's-length interactions (Sharma \& Choudhury, 2014), despite claims that strategic forms of interactions are more efficient (Vachon et al., 2009).

Additionally, the characteristics of arm's-length interactions include formal, infrequent communication, no or small investments in the interaction, and a high focus on price (Bowersox, 1992). This is illustrated by the findings of Jazairy (2020a), where shippers tend to write short-term contracts to be able to leverage LSPs, whilst LSPs do not communicate green logistics offerings once contracted to a shipper due to e.g. additional costs. In addition to being formal and infrequent, illustrated by information exchanges that are lacking, or are one-sided (see e.g. Wolf \& Seuring, 2010), communication can also be hindered by the use of different environmental terms (see e.g. Murfield \& Tate, 2017).

\section{Collaboration}

Collaboration requires a high level of commitment and trust, in addition to long-term commitment and a high level of information-sharing (Spekman et al., 1998; Touboulic \& Walker, 2015). In addition, collaboration requires investments in interaction-specific assets, knowledge exchange, shared resources, and capabilities, as well as governance mechanisms (Dyer \& Singh, 1998; Touboulic \& Walker, 2015). Striving for collaboration can be costly and requires extensive commitment from both organizations. This is exemplified by Vachon and Klassen (2008), who describe cases where shippers initiate supplier initiatives, or where suppliers react to customer needs and initiate suitable initiatives. Organizations can often have both collaborative elements in their interactions, e.g. some information linkage and joint planning, but this does not equate to collaboration, which requires a new strategic orientation, additional resources, and commitment (Spekman et al., 1998). This implies, in line with Touboulic and Walker (2015), that true collaboration is difficult to achieve.

Collaboration is frequently discussed and proposed as a way to improve overall logistical performance (see e.g. Stank et al., 2001), or to improve the environmental performance of supply chains (e.g. Vachon \& Klassen, 2008; Touboulic \& Walker, 2015). Collaboration as a way to implement environmental initiatives is suggested as joint planning to reduce the environmental impact of products and processes between supply chain organizations (Vachon $\&$ Klassen, 2008). It is also important to note that in order to achieve collaboration, many functional areas within the organizations need to interact, and not just e.g. the logistics function (Bowersox, 1992).

In the green logistics literature, collaboration is suggested as a facilitator to implement new technology or innovations (Carter \& Rogers, 2008). One key requirement for collaboration is a long-term commitment and investments in the interaction itself (see e.g. Dyer \& Singh, 1998). This can be illustrated by the findings of Jazairy (2020a), showing that long-term contracts enable LSPs to invest in green and "for-the-interaction"-specific assets, such as biofuel technology. Collaboration also allows for increased resource pools and shared investments in infrastructure or technology, for example (Soosay et al., 2008). Individually, organizations may 
have scarce resources to become greener, but with joint planning and shared resources, organizations can increase their efficiency and thus become greener (Bowersox, 1992; Cao \& Zhang, 2011).

\section{Continuous scale of interaction}

In between the extremes is the middle-range area, i.e. interactions that cannot be classified as either arm's-length or collaboration. As described by Cooper and Gardner (1993), this range can be seen as a continuous scale, meaning that the characteristics of different interactions do not necessarily differ significantly. Cooperation and coordination are two terms that reoccur in the literature, but some authors regard them as distinct forms of interaction (e.g. Spekman et al., 1998; Soosay \& Hyland, 2015), whilst other considers them as interaction mechanisms (e.g. Bowersox, 1992; Touboulic \& Walker, 2015). Interactions differ based on a relative scale (Soosay \& Hyland, 2015), where an interaction may be more collaborative or more arm'slength than another interaction. This distinction will be used in this thesis.

\subsection{Implementation of green practices}

The implementation of logistics practices has been explored by various authors within different logistics areas, e.g. innovation (Flint et al., 2005), sustainable innovation (Björklund \& Forslund, 2018), or logistical change (Barbosa \& Musetti, 2011), but all authors conclude that there needs to be additional research on the subject. Different authors have had different focuses, as can be seen in Table 2.2. In addition to logistics, implementation processes have been explored in other areas, e.g. total quality management in the shape of the PDSA (Plan, Do, Study, Act) cycle (Deming, 1986), which logistics researchers have turned to in order to gain additional knowledge. Regardless of field or area, implementation processes share similar traits, which allows for implications of the implementation of GLPs (da Mota Pedrosa et al., 2015). The common denominator for different implementation processes is the distinction between different phases. Different approaches include varying numbers of phases, but the content aligns to a great extent. For the implementation of green logistics practices, the overall phases suggested in this thesis are: (1) Identifying needs and designing green practices; (2) Operationalization of green practices; and (3) Follow-up on the green practice (see e.g. Busse \& Marcus Wallenburg, 2011; da Mota Pedrosa, 2012). 
Table 2.2. Implementation of green logistics practices adapted from literature

\begin{tabular}{lll}
\hline Reference & Focus of the paper & Phases \\
\hline Flint et al. (2005) & $\begin{array}{l}\text { Begin to construct a theory of } \\
\text { logistics innovation from the } \\
\text { ground up, as the field is } \\
\text { scarcely explored. }\end{array}$ & $\begin{array}{l}\text { Setting the stage activities; Customer } \\
\text { clue gathering activities; Negotiating, } \\
\text { clarifying and reflecting activities; } \\
\text { Inter-organizational learning. }\end{array}$ \\
$\begin{array}{lll}\text { Busse \& Wallenburg } \\
\text { (2011) }\end{array}$ & $\begin{array}{l}\text { Literature review of innovation } \\
\text { management in LSPs. }\end{array}$ & $\begin{array}{l}\text { (1) Innovation generation, based on the } \\
\text { four steps suggested by Flint } \text { et al. } \\
\text { (2005); (2) Innovation adaptation. }\end{array}$ \\
Hisano Barbossa (2011) & $\begin{array}{l}\text { The use of a performance } \\
\text { measurement system in a } \\
\text { logistical change process. }\end{array}$ & $\begin{array}{l}\text { (1) Events that trigger change; (2) } \\
\text { Change program and management; (3) } \\
\text { Results of change. }\end{array}$ \\
Da Mota Pedrosa (2012) & $\begin{array}{l}\text { Exploring how LSPs integrate } \\
\text { customers during innovation } \\
\text { development. }\end{array}$ & $\begin{array}{l}\text { (1) Idea generation; (2) Development; } \\
\text { (3) Implementation }\end{array}$ \\
$\begin{array}{ll}\text { Exploring the processes for } \\
\text { implementing sustainable } \\
\text { logistics innovation. }\end{array}$ & $\begin{array}{l}\text { (1) Idea generation; (2) Selection of } \\
\text { ideas; (3) Concept development; (4) } \\
\text { Implementing and learning. }\end{array}$ \\
\hline
\end{tabular}

Identifying needs and designing green practices start by identifying needs to become greener, in accordance with the definition of a process (as used by e.g. Flint et al., 2005; Ljungberg \& Larsson, 2012). The first phase in the implementation of GLPs is therefore to acknowledge some sort of disturbance, pressure, or request to green logistics. This includes customer pressures (e.g. Chu et al., 2019), regulatory compliance (e.g. Walker et al., 2008), gaining a potential competitive advantage (e.g. Sarkis, 2003), and increased efficiency (e.g. Kumar et al., 2012). These can then be converted into opportunities, which can be translated into new or improved services (see e.g. da Mota Pedrosa, 2012). Björklund and Forslund (2018) highlight the importance of including other supply chain organizations in the first phase, consistent with both Flint et al. (2005) and da Mota Pedrosa et al. (2015). Additionally, as in the definition, processes aim to create value for the customer, which can be either an internal customer (e.g. competitive advantage or increased efficiency) or an external customer (e.g. customer pressure or regulatory compliance) (Ljungberg \& Larsson, 2012).

The first phase also includes the design of GLPs. This includes identifying and forming potential GLPs and the hypothetical testing of the GLPs, where customers are presented with descriptions and offered the opportunity to react to the proposed GLP (da Mota Pedrosa, 2012). Similarly, Flint et al. (2005) describe this as customer clue gathering, observing that LSPs invited customers (e.g. shippers) to provide insights into and suggestions for identifying potential needs or improvements, e.g. GLPs. The design of GLPs can also include other supply chain organizations, and the selection of which GLPs to advance in the process can be based on e.g. available resources, either at the LSP or in the collaboration with other supply chain organizations (see e.g. Björklund \& Forslund, 2018). The design of GLPs also includes gathering information regarding hidden or actual customer needs, for example price ranges, which in turn affects which potential GLPs should be pursued (Flint et al., 2005; da Mota 
Pedrosa, 2012). Additionally, business analyses can forecast the potential success of a GLP and determine whether or not it should be operationalized (da Mota Pedrosa et al., 2015).

The second phase identified in the literature was the operationalization of the GLPs. This includes testing the chosen GLP, before fully upscaling the operationalization of the GLP (da Mota Pedrosa, 2012; Björklund \& Forslund, 2018). Operationalization could also be a platform for re-innovation, where the chosen GLP could be further developed, or could act as an input for additional processes of implementing GLPs (Björklund \& Forslund, 2018). This is also supported by the implementation process as presented by Flint et al. (2005), where it is depicted as a cyclic process, or as illustrated by the PDSA cycle (Deming, 1986). In the operationalization phase, close interaction between shippers and LSPs is advocated to anticipate potential challenges or problems (see e.g. da Mota Pedrosa, 2012).

The last phase of the process of implementing GLPs is follow-up. Follow-up can involve either performance measurement of the operationalized GLP (Barbosa \& Musetti, 2011) or reflecting on successful factors and failures in the implementation process itself (Björklund \& Forslund, 2018). Such reflections can result in organizational learnings, which in turn could be the basis for potential new GLPs, thus starting the endless loop of greening logistics (see e.g. Flint et al., 2005) The latter applies to e.g. LSPs that could implement GLPs for one haulage operator in order to gain organization learnings, and then implement improved GLPs for another haulage operator, i.e. reporting back successful GLPs (see e.g. Björklund \& Forslund, 2018). 



\section{Methodology}

This chapter presents the rssearch methodology. First, the research approach is presented. This is followed by the research process. The third section presents the research methods that have been used, both for the appended studies, but also for the thesis frame. The chapter concludes with discussing research quality.

\subsection{Research approach}

The purpose of this thesis is to explore how supply chain interaction can facilitate logistics service providers to implement green logistics practices. The greening of logistics has gained increased interest. However, little of this research has been dedicated towards the LSPs and the interactions they need to form to become greener (see e.g. Evangelista et al., 2018). Because of that, this thesis uses an explorative approach, as explorative approaches are suitable when investigating a known problem from a new angle and to provide new knowledge within an area (Arbnor \& Bjerke, 1994; Patel \& Davidson, 2011). However, despite the overall approach being explorative, parts of the research were descriptive in its approach. The first research question that aims to describe GLPs was answered using a descriptive approach. As GLPs have been thoroughly examined prior to this thesis, a descriptive approach was considered appropriate. Descriptive approaches are suitable when an area has already been studied and focuses on identifying relations, characteristics, or categorizations within a phenomenon (Patel \& Davidson, 2011). Similar to the purpose, both the second and third research questions used an explorative approach. The forms of interaction needed to implement green logistics practices are seldom investigated, despite research that focuses on interaction as a prerequisite for the implementation of green logistics practices. In addition to the forms of interaction scarcely studied, the implementation process is also scarcely investigated, especially with a focus on interaction.

When conducting research, studies can be distinguished as being deductive or inductive (Bryman \& Bell, 2015). The latter refers to the formulation of hypotheses or propositions based on existing theoretical knowledge and testing them empirically. In inductive studies, the goal is to generate theories based on observations (Bryman \& Bell, 2015). Overall, this research has been primarily deductive, but some parts have been inductive. The main concepts of this thesis are derived from literature, e.g., interaction as a way to understand the interplay between LSPs and other organizations and tested empirically and are therefore deductive. However, in some instances, the research has been inductive, for instance, identifying interactions needed to implement GLPs or identifying organizations outside of the supply chain involved in the implementation of different GLPs.

\subsection{Research process}

This licentiate thesis is a compilation thesis based on three papers and a case report. The papers are the products of four different studies which overlap. The different parts that are compiled by the thesis frame are presented below in Table 3.1. Thus, the research process consists of five parts: the thesis frame, the three papers, and the case report. 
Table 3.1. Parts of the research process

\begin{tabular}{|c|c|c|c|}
\hline Parts & Product & Focus & Contribution \\
\hline Study 1 & Paper I & $\begin{array}{l}\text { Inter-organizational interaction } \\
\text { for sustainable supply chains }\end{array}$ & $\begin{array}{l}\text { Purpose, Research Questions, } \\
\text { overall analysis, Contributions }\end{array}$ \\
\hline Study 2 & Paper II & $\begin{array}{l}\text { Roles and perspectives when } \\
\text { measuring the environmental } \\
\text { performance of an urban } \\
\text { consolidation center }\end{array}$ & $\begin{array}{l}\text { Interaction needed in the follow- } \\
\text { up phase, implementation as } \\
\text { phases, understanding of } \\
\text { consolidation centers as a mean } \\
\text { to increase fill rates. }\end{array}$ \\
\hline Study 3 & Paper III & $\begin{array}{l}\text { Interactions needed when LSPs } \\
\text { implement alternative fuel- } \\
\text { solutions. }\end{array}$ & $\begin{array}{l}\text { Interaction needed in the first } \\
\text { two phases, implementation as } \\
\text { phases, understanding of } \\
\text { alternative fuel. }\end{array}$ \\
\hline Study 4 & Case Report & $\begin{array}{l}\text { Interaction between Shippers and } \\
\text { LSPs in the early phases of } \\
\text { implementing GLPs }\end{array}$ & $\begin{array}{l}\text { Interaction needed in the } \\
\text { identifying needs and design } \\
\text { phase, Understanding of several } \\
\text { GLPs. }\end{array}$ \\
\hline
\end{tabular}

The research process started when the author joined a systematic literature review study (Study 1), which began prior to the start of the research process. Since the first study was a literature review that explored inter-organizational interaction for sustainable supply chains and its development in scientific journals over time, it gave an introduction to and an understanding of green logistics and supply chain interaction. The participation in Study 1 helped identify interaction as a means to explore the interplay between LSPs and other organizations when implementing green logistics practices. It highlighted that the combination of focuses on LSPs and interaction with other organizations was missing within the area. Of particular interest for this thesis was the identification of requiring a broader empirical scope, as organizations can have different roles and perspectives. Thus, Study 1 would strongly contribute to the formulation of the purpose and identify relevant literature that could be used when writing the thesis frame.

Following the first study was a study focusing on the different roles and perspectives needed when measuring the performance of an urban consolidation center (Study 2). As the first study had highlighted the need to have a broader empirical scope, the different roles and perspectives organizations had in measuring the performance of a consolidation center were of interest to capture. Additionally, to mediate the different perspectives between different roles, interaction was required. The study's focus on the performance measurement of a consolidation center gave an understanding that follow-up is essential to deem an implementation of a GLP as successful and enable continuous work with greening the logistics. The second study contributed with an understanding that the implementations of GLPs are long processes, which are not completed until desired effects are achieved. Additionally, it gave that in supply chains, many organizations are affected by the changes in the operations of LSPs. Study 2 was essential for the development of this licentiate thesis. It gave an understanding of how important interaction is in the follow-up phase of implementing GLPs, and that it would be interesting to study interaction throughout the other phases of implementing GLPs. 
The third study built upon that interaction between different organizations could facilitate the implementation of GLPs and interests of investigating interaction through different implementation phases, as established after the second study. In the third study, the interactions formed when implementing alternative fuel into an LSPs fleet were explored. This could explain how LSPs can implement GLPs without solely taking the costs of such implementations. In the third study, organizations outside of the supply chain proved important for an implementation, which was of interest to investigate further. The idea that interaction could help LSPs to implement GLPs may have been found and formed in the first two studies but was refined during the third study. The third study highlighted the need to consider LSPs as large organizations that consist of different functions in several business areas. In order for an LSP to implement GLPs, these functions need to interact with each other and functions at other organizations. This gave an understanding that LSPs must interact internally to implement GLPs, which were of interest to study further in addition to interacting with other organizations.

During the latter parts of writing the thesis frame, an opportunity to study organizations interacting in order to become greener arose. In that case, a Shipper and a LSPs decided to join forces and become greener together. This allowed studying how shippers and LSPs interact in the early phases of implementing GLPs, which was not covered by the previous three appended studies. As previously stated, it was of interest to study interaction in different phases of implementing GLPs, and that internal interaction and external interaction were of interest to study. The study aligned with those research interests. One of these studies resulted in the workin-progress case report used as empirical input to this licentiate thesis.

The research process with its components is visualized in Figure 3.1 below. The dashed line in Study 1 corresponds to the study's start prior to the start of the process for the licentiate thesis. The writing of the thesis frame is illustrated as the orange line in the figure. The studies include the processes of writing and publishing papers.

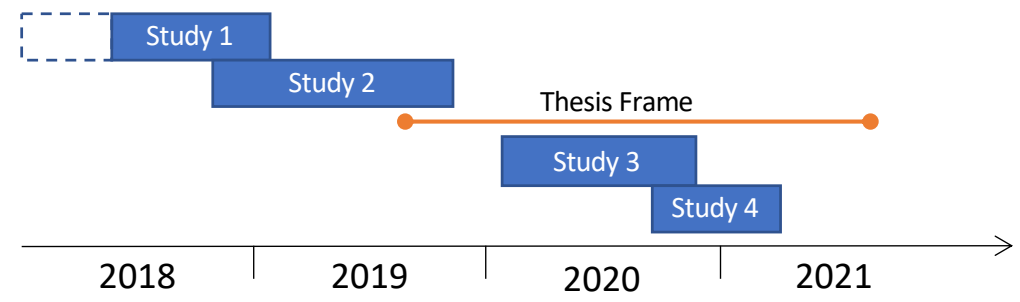

Figure 3.1. The research process 


\subsection{Research methods}

As presented in chapter 3.2, the research process consists of several studies in which different methods are applied. Mainly, two different types of methods are included in the papers and described further below: literature review and case studies. Additionally, the methods for the analyses in the thesis frame are described. The methods that have been used in the different studies are highlighted below in Table 3.2.

Table 3.2. The methods used in the studies

\begin{tabular}{cccc}
\hline Studies & Narrative Literature Review & Systematic Literature Review & Case Study \\
\hline Study 1 & & $\mathbf{X}$ & \\
Study 2 & X & & $\mathbf{X}$ \\
Study 3 & X & & $\mathbf{X}$ \\
Study 4 & & $\mathbf{X}$ \\
\hline
\end{tabular}

\subsubsection{Literature Reviews}

Literature reviews are an appropriate way of gaining understanding and knowledge about a specific research area (Bryman \& Bell, 2015). Literature reviews can be used to identify important references, what has already been covered, and what is missing (Tranfield et al., 2003). In this thesis, two types of literature reviews have been conducted: narrative literature reviews and systematic literature reviews. Both types of literature reviews are expanded upon and described below.

\section{Systematic Literature Review}

Systematic literature reviews are more focused, structured, and replicable literature reviews (Tranfield et al., 2003). It uses predetermined search terms and includes documentation of findings and results. The first study used a systematic literature review and focused on interorganizational supply chain interaction (IOSCI) for sustainability. A systematic literature review was chosen because it is commonly used to summarize different areas within a field and to identify potential gaps (Tranfield et al., 2003). The purpose was to advance the understanding of the logistics and supply chain management literature on IOSCI for sustainability by describing and synthesizing the existing knowledge, the development of the research over time, and to propose a future research agenda. As of that, a systematic literature review was a suitable method.

The study was designed and initiated prior to the participation of this author and was so in accordance with how to conduct systematic literature reviews (see e.g. Tranfield et al., 2003; Touboulic \& Walker, 2015b). This author entered to process once the literature review was expanded with additional papers. In the expansion, 234 papers were added to the initial 393 papers taken through the review process. All of the included papers were reviewed by at least two persons, and all the members of the review filled in a spread-sheet coding formula to ensure structure and replicability (Tranfield et al., 2003). The review was conducted stepwise, narrowing the total 627 papers down to 87 papers included in the final analysis. The basis for the final analysis were trend charts that visualized the development of chosen subjects within the field over the span of 2000 to 2018 . These trends focused on e.g., methods, unit of analysis, empirical scope, the origin of the studied organizations. From the trends that were analyzed, a 


\section{Methodology}

number of future research agendas could be proposed. This author participated in the analysis of the additional papers.

\section{Narrative Literature Reviews}

Narrative literature reviews are less focused and enable a broad scope to scan an area (Bryman $\&$ Bell, 2015) and allows the usage of techniques such as the snowballing approach when one follows the citations in the references that point to other references. In this thesis, narrative literature reviews were foremost used to formulate the purpose and research question and to create the theoretical framework. As narrative literature reviews have a larger scope than systematic literature reviews (Bryman \& Bell, 2015), they are appropriate for building a theoretical framework since they allow the researcher to be open to new findings and to gain increased knowledge. The narrative literature review has been an important step in the research process and has been conducted in the thesis frame, Study 2, and Study 3. The narrative literature reviews were similar in their approaches and started with combining relevant keywords to identify relevant references. For instance, to the thesis frame, different combinations of synonyms for logistics, interaction, and green were used to identify relevant references for the introduction, which contained concepts for the purpose and for the thesis frame. These references could later be used for creating more specific search strings for the frame of reference. The results of the searches were often scanned for references with a high number of citations, and through these references, the snowballing technique was applied to find other relevant literature on the same topics. The narrative literature reviews were primarily performed in the database UniSearch, which links to several other databases such as Scopus and Web of Science. As a complimentary database, Google Scholar was used. First, the titles were scanned, eliminating references with the wrong focus, followed by reading the abstracts. If the titles and abstracts seemed relevant, the references were saved, and relevant parts were highlighted and often commented upon, not to lose track of any relevant information.

\subsubsection{Case Studies}

All of the empirical data included in the thesis frame have been gathered through case studies. Case studies are a method of investigating or study a contemporary phenomenon in a real-world context and are suitable when the researcher sets out to explore how or why social-phenomenon work and when the researcher has no control over behavioral events (Yin, 2014). For instance, Study 2 explores how roles and perspectives affect the performance measurement of a consolidation center, while both Study 3 and Study 4 explore interaction when implementing GLPs - all social-phenomenon in their contexts. Another distinction when choosing a case study as a research method is to use either a single or multiple case study (Yin, 2014). In this thesis, the appended case studies are all single case studies. Despite the inclusion of three case studies, all of these studies were diverse and included very different selection criteria and data collection methods. These are elaborated upon in the following sections.

\section{Selection of Cases}

According to Yin (2014), the unit of analysis defines the cases and thus also distinguishes the selection criteria for the studies. In the first case study (Study 2), the objective was to find a case that successfully had managed to measure and quantify the effects from an urban consolidation center. In an initial internet scan, one such successful performance measurement was found. Additionally, this performance measurement was described in a research report, which contained information about included organizations, and thus describing which organizations to target and include in the case study. The reason for applying a case study was the need to investigate how different organizations were involved in the performance 


\section{Methodology}

measurement and to describe the roles and perspectives of the involved organizations. Roles and perspectives are social phenomena, which case study allows to be studied in its context (in line with Yin, 2014). Thus, the unit of analysis became the inter-organizational interaction needed and the roles and perspectives of the involved organizations in the performance measurement.

The second case study (Study 3) set out to study the interactions formed when LSPs implement innovative technology as GLPs. Case studies allow researchers to investigate behaviors over which the researcher has no control (Yin, 2014). The study followed the interactions that were formed, e.g. behaviors of actors and organizations, and case study were deemed suitable. In line with Yin (2014), a set of selection criteria were applied in order to find a suitable case. The selection criteria consisted of finding an LSP that recently had or was in the process of implementing GLPs. Additionally, the organization was required to provide information of other organizations with whom they had interacted to implement the GLP. A partner organization in a research project was identified as a potential fit after the environmental manager of the organization mentioned an ongoing process of implementing liquefied biogas technology into one of their haulers. Thus, the case fitted the criteria. Due to convivence (Bryman \& Bell, 2015), only Swedish cases were targeted in both the first and the second case study.

In the third case study (Study 4), no selection process occurred, as the organizations asked for involvement from the academia. This is in line with what is proposed by Dubois \& Gadde (2014), that similar to how researchers select cases, sometimes the researchers are connected with a particular reality that provides opportunities for identifying existing research phenomena; thus, the case selects the researcher. When the Shipper and the LSP decided to design and implement green logistics practices collaboratively, the Shipper reached out to Linköping University and asked for their involvement and to find a neutral meeting ground for both organizations. Both the Shipper and the LSP have been involved in research projects targeting green logistics with Linköping University in the past, and both organizations have shown an interest in engaging in and practicing green logistics. The inquiry for the participation coincided with the licentiate thesis' purpose, as a Shipper and an LSP were interacting in order to implement GLPs and become greener. Thus, the case fitted into the scope of the thesis and was chosen to be explored further.

\section{Data collection}

Collecting data from case studies can be done using various methods, such as interviews, observations, and document scanning (Yin, 2014). Additionally, data can be either qualitative or quantitative (Bryman \& Bell, 2015). Both the first and the second case study used interviews as the main data collection method. The interviews were foremost semi-structured interviews with open-ended questions. In each case, the interview guides were similar for the interviews held in each case study but adjusted slightly with regard to the respondent. In the first case study, five interviews were held, each lasting between 30-50 minutes, and were recorded to be able to go back to the source material after the interviews were held. Two researchers were always present during the interviews to avoid biases and ensure that all relevant information was captured. As the research report had described both the performance measurement and included organizations, the interviews foremost focused on the roles, perspectives, and interaction of the organizations described in the report.

The second case study contained three in-depth interviews that lasted for about 60 minutes each. Interviews were recorded, and respondents were provided with written summaries of the 


\section{Methodology}

interviews afterward and offered to review their statements. In the second case study, the respondents were asked to list other important organizations for the implementation. This resulted in three interviews held with the LSP, the haulage operator, and the fuel-provider, respectively. However, the shippers in the study were highlighted as an important actor but were kept anonymous by the LSP due to the uncertainty of the new technology in the initial implementation phases, which hindered the researchers from interviewing them. However, the haulage operator ensured that their view of the interaction would confirm the data that was already gathered. In both cases, data from the interviews were either triangulated during other interviews or with complementary data-scanning, in line with Yin (2014).

The third case study (Study 4) relied on participant observations (Bryman \& Bell, 2015) as the data-gathering method, opposed to interviews that were the main data-gathering method in the other two case studies. Participant observations are when the researchers join a group for an extended period of time, observing behaviors, such as interactions between individuals or reactions, and what is said during meetings and gatherings. In the third case study, data have been gathered from three meetings between the Shipper and the LSP, and one internal workshop at the Shipper. The meetings lasted between two and four hours, and all meetings were hosted by either the Shipper or the LSP. Several participants from both organizations, that represented different functions or business areas within the organizations, participated in the meetings. Two researchers were always present during the meetings to ensure reliability and trustworthiness. According to Bryman \& Bell (2015), participant observations acknowledge the researchers as fieldworkers, allowing other participants to ask questions to the researchers but also allows the researchers to ask questions. Additionally, participant observations are often complimented with interviews, which are planned to occur in the future.

\section{Data Analysis}

Analyzing case data were foremost relevant for the first case study (Study 2) and the second case study (Study 3), as the third case study (Study 3) consisted of compiling the data gathered into a description of the case (a case report). The analyses for the data of the two cases were based on a similar strategy, where the data were categorized in order to find evidence that could support, contradict, or add to the concepts identified within the literature. A similar approach is described by Yin (2014), who describes the sorting of data into arrays or matrices, which then can ease the analysis of data using different strategies. One such strategy, to work the data from the "ground up" is an inductive approach of analyzing the data, in contrast to the deductive approach of collecting data, and is suitable for examining the data to find evidence that can add to, contradict or support previously identified concepts (Yin, 2014).

This strategy was used in both the first and second case studies, but with different ways of performing the actual categorization. In the first case study, the categorization of empirical data used a framework created by Persdotter Isaksson et al. (2019) that lists activities in the environmental logistics performance management process to categorize the data. From these categorizations, propositions could be found, which were that organizations had different roles and perspectives of the performance measurement. In the second case study, no initial framework to guide the categorization could be identified. Instead, the data were categorized inductively into three categories guided by the purpose of the study. The categories were which organizations that interact when implementing alternative fuel as a GLP (who), the form of interaction between the organizations (what), and lastly, when in the implementation process the interaction occurred (when). From these three categorizations, the concepts could be derived that LSP must interact with other organizations, with different forms of interaction, during different stages of implementation. 
For the third case study, the empirical data gathered from the observations have been compiled into a case study. The analysis of the empirical data from the third case study is performed within the thesis frame and described below in chapter 3.3.3.

\subsubsection{Methods for analyses in thesis frame}

\section{Describing GLPs to include the need for interaction}

The analysis of research question 1, to describe green logistics practices, had contributions from both the literature and empirical findings from the Papers. The analysis can be considered twofolded, where first, empirical data on GLPs needs to be matched with "generic" GLPs or as GLPs are described in the literature. This was done by identifying GLPs that are commonly reoccurring within the literature. The description of GLPs could then be used to identify what GLPs that were found within the different cases. This is similar to what is described as Pattern Matching by Yin (2014), where empirical data is matched with predetermined or predicted patterns.

Second, the analysis consisted of finding properties within the identified GLPs that could describe them so that they included the need for interaction. This second step of the analysis resembles the strategy of analyzing data as described above, where the data is worked "from the ground up" to find any patterns or emerging concepts (see e.g. Yin, 2014). This resulted in the identification of two themes that were found inductively by searching for reoccurring descriptions of either requiring interaction with other organizations when implementing GLPs, or effects that GLPs have on other organizations. The two themes identified were motives and organizational level of decision and impact.

\section{What forms of interaction that can occur when implementing GLPs}

The analysis of research question 2, which aimed to explore what forms of interaction that occurs when implementing GLPs, was divided into three steps and executed in sequence. First, Study 2, Study 3, and Study 4 were described to depicted what organizations that were included in the implementation of the GLPs in their respective study and what organizations that interacted with other organizations. This can be described as rearranging the data from the cases in the studies to gain a better foundation for the actual analysis (see e.g. Yin, 2014). Once the data were rearranged, it gave an overview of included organizations and which organizations that interacted with other organizations within the cases.

Second, the analysis targeted the identified interactions, which were explored to understand what constituted the interactions. The second step used Pattern Matching (see Yin, 2014). Empirical data on what constituted the interactions were explored using parameters that can decide the form of interaction, found in the literature. The parameters were information sharing, transferring knowledge, sharing resources, and communication. Two additional parameters, trust, and commitment were also used, but as opposed to the other four parameters, trust and commitment were expressed through the other parameters and not as explicit parameters. For instance, one organization can illustrate trust by sharing a specific type of information or commitment through investing and sharing resources in a specific interaction.

The third and final step was to identify what form the identified interactions had, based on what the interactions consisted of. What the interactions consisted of had been described using the parameters in the second step. Thus the final step consisted of investigating how much of each parameter the interactions consisted of to conclude the form of interaction, based on a range 


\section{Methodology}

suggested in the frame of reference. For instance, if one interaction showed signs of deep commitment and sharing important information frequently, the interaction could be determined as a close form of interaction. This step of the analysis decided what form of interaction that occurred between the organizations, identified in the first step.

\section{What characterizes the interaction that occurs in the different phases of implementing GLPS.}

The analysis of research question 3, which aimed to explore what characterizes the interaction that occurs in the different phases of implementing GLPs, consisted of exploring how the interactions found in research question 2, changed over time. This was done using a similar approach to what has already been described. The data were analyzed to find emerging patterns on how the interactions changed with respect to the process of implementing GLPs (in line with Yin, 2014). The categorization consisted of analyzing each interaction to find different characteristics for the interaction during the implementation process. Synthesizing all interactions gave an emerging pattern on how the interactions changed during the course of the implementation process. This analysis gave three categories, where each category represented a phase, which was "Identifying needs and designing GLP", "Operationalizing the GLP", and "follow-up". Based on the distinction of phases, all of the interactions within each phase could be given generalized characteristics.

\subsection{Research quality}

According to Bryman \& Bell (2015), two of the most common criteria for research are reliability and validity. Reliability concerns whether or not a study is repeatable, which can be exemplified through thorough documentation and conducting research in as many operational steps as possible (see e.g. Yin, 2014). This includes being consistent in describing and using methods to achieve desires outcomes. Bryman \& Bell (2015) suggests that reliability in qualitative research can be hard to achieve, as it is near impossible to mimic a certain social setting, but nevertheless, it can be achieved by including more than one researcher to ensure that what is seen or heard is what is actually said. In all of the appended studies, at least two researchers have always been present and participated in the data gathering. This allowed the researchers to compare their perceptions and to find agreements on the data gathered. Additionally, in the interviews and the observations in case studies, summaries of what was gathered were always offered to the respondents or participants in order for them to review their statements and ensure their information was not altered.

Validity strongly links to reliability, as without validity refers to whether or not the researcher is observing or exploring what they say that they are (Bryman \& Bell, 2015). Thus, without proper documentation and high reliability, the validity of the researcher cannot be ensured. Yin (2014) states that validity is whether or not the research results are generalizable or applicable in other contexts. Validity can be achieved through triangulation, using different methods or sources of data in the study of social phenomenon (Bryman \& Bell, 2015). This has been applied in the case studies, where either data gathered from interviews were triangulated using observation of documents or gather data from other respondents. According to Yin (2014), validity can be ensured by early stating the explorative purpose. This allows a theoretical proposition to support the explorative purpose. For instance, to explore how interaction can facilitate LSPs to implementation green logistics practices, which is the purpose of this study. 



\section{Appended papers}

In this chapter, summaries of the appended papers and how they contribute to the thesis are provided. This is presented for each paper respectively.

\subsection{Paper I - Inter-organizational supply chain interaction for sustainability}

\subsubsection{Summary of Paper I}

This paper takes as its point of departure the fast-growing trend of research on interorganizational supply chain interaction (IOSCI) for sustainability. Despite well-defined problems, research on IOSCI for sustainable supply chains is fragmented and it is uncertain whether previously purposed research gaps have been closed. Thus, the purpose of Paper I was to advance the understanding of the logistics and supply chain management literature on IOSCI for sustainability, by describing and synthesizing the existing knowledge and the development of research over time, and by proposing a future research agenda.

The paper uses a systematic literature review (SLR), in which 627 papers were put through the process of the SLR (e.g. abstract scanning, collecting articles, and reading full papers) and 87 papers formed the basis of the analyses. Logistics and supply chain management journals were targeted, and articles published within these journals were the unit of analysis. The analysis consisted of trend analyses, where the development of publications over time was analyzed for topics such as the number of articles by year, the targeted sustainability dimension, and the empirical scope. The findings suggested that there is an increased focal firm perspective, the gap between environmental and social dimensions is increasing, and Asian studies are growing faster than studies in other regions. The outcome was a future research agenda based on the trends and gaps identified.

\subsubsection{Contribution to the thesis}

Paper I helped to identify relevant literature for the frame of reference, and to form and anchor the purpose of the licentiate thesis in relevant and up-to-date problems and gaps. The trend analyses and identification of gaps helped with understanding what was missing within the field, and with forming a research interest. For instance, in the future research agenda developed in the paper, research aspects, examples of research topics, and suggested methodologies were proposed. For example, it was concluded that future research should address LSPs to cover their large share of the environmental footprints of logistics, and that future research should address perceptions on the inter-organizational interaction of different actors within organizations (e.g. intra-organizational interaction) and between different organizations. Thus, research should focus on LSPs and their interactions to reduce environmental impact, both internally between different actors and externally with other organizations and their actors.

Paper I helped position the thesis toward the field of green logistics, supply chain interaction, and the focus on LSPs, and also helped with gathering empirical data from different organizations and actors. Thus, Paper I contributes to the literature-based chapters (e.g. the introduction and the frame of reference) by identifying relevant literature for the thesis, as well as positioning the thesis's contributions. Despite not being directly connected to a research 


\section{Appended papers}

question, Paper I contributes to the overall analysis and discussion, as well as acknowledging several research gaps which this thesis aims to positioning itself against. Thus, Paper I was important both for formulating the licentiate thesis purpose and for designing the other papers included in the thesis framework.

\subsection{Paper II - Roles and Perspectives When Estimating Energy and Environmental Potentials of Urban Consolidation}

\subsubsection{Summary of Paper II}

Paper II takes its point of departure in the performance measurement of an urban consolidation center (UCC). There are few studies measuring the actual performance of UCCs, and the overall aim of the paper is to increase the knowledge regarding estimating the benefits from implementing UCCs, with a special focus on MCCs (municipal consolidation centers), and on the roles and perspectives of the involved actors. The GLP increase fill rate encompasses consolidation centers, which was the focus of this paper.

The paper used a case study design, where an initial internet scan identified a documented case in which the performance of consolidation centers had been measured. The participating organizations from that case were targeted for interviews, in order to supplement the case report with a focus on the roles and perspectives of the participating organizations, and on the interaction between them. The findings indicated that in order to successfully measure the environmental performance of a consolidation center, several organizations need to be involved in the process. The paper concluded with an overview of the different roles and perspectives of the involved organizations in the performance measurement.

\subsubsection{Contribution to the thesis}

The findings of Paper II indicated that different organizations possess different types of information, and act as facilitators with different motivations for the successful implementation and operation of an MCC. Organizations need to take on different roles, with respect to their competences, in order for an evaluation of the performance outcomes to be carried out. Different organizations also have different perspectives of benefits and effective performance, further highlighting the need to involve several organizations. Additional findings suggest that communication, mutual understanding, and interaction are important for successfully evaluating consolidation centers, as communication is important for establishing mutual understanding and sharing knowledge about different parts of the logistics system.

Paper II gives insights into the last phase of implementing GLPs and helps with understanding the interactions that occur in the follow-up phase. Since the context of Paper II is a consolidation center, it also gives some understanding of how consolidation centers, as a solution for increasing fill rates, can be described empirically. Additional insights regarding interaction and communication from the study can also be used in the analysis of what interactions consist of in the last phase of implementation, as well as the interaction required to operate a consolidation center. 


\subsection{Paper III - Interaction for Successful Implementation of Climate Smart Freight Technology}

\subsubsection{Summary of Paper III}

Paper III takes its point of departure in the process of implementing new fuel technology, and the fact that LSPs are required to interact with many other organizations throughout the implementation process in order to successfully implement emerging fuel technologies. This led to the purpose of Paper III, which was to increase the understanding of ways to interact in order to successfully implement emerging fuel technologies, by focusing on the actors involved (who), the forms of interaction (how), and the different steps of the implementation (when). The GLP alternative fuel was the main context for the paper.

The paper studied a case of an LSP implementing liquified biogas (LBG) at one of its haulage operators, in order to successfully transition the entire fleet to become fossil free. Interviews were held with different actors and organization, and a framework to analyze the identified interactions and assess the forms of interaction was created based on literature. The findings showed that in order to implement LBG into a fleet of freight vehicles, various forms of internal and external interaction were needed. The empirical data suggested that interaction between two organizations could vary with regard to the phases of the implementation process. Some organizations that were viewed as important in the literature (e.g. vehicle and technology providers) were unimportant to the implementation in the study of the paper. Instead, two internal interactions and five external interactions were identified, and were suggested in the paper to be important for the successful implementation.

\subsubsection{Contribution to the thesis}

By mapping the important organizations for the implementation of alternative fuel, Paper III provides an understanding of which organizations need to be interacted with and which organizations do not. For instance, the fuel provider was found to be an important organization to interact with in order to successfully implement alternative fuel. Additionally, it was concluded that internal interaction within the LSP was important, especially as a facilitator, linking the fuel provider and the haulage operator. The framework crated in Paper III, which analyses interactions based on dependency, commitment, frequency and standardization of communication, price or service focus, and investments in the interaction, is also the basis for how interaction is analyzed in the thesis. Thus, Paper III is closely connected to the second research question.

Paper III also provides insights into the GLP alternative fuel, as this was the context in which interactions were studied, which contribute to the first research question. Paper III also contributes to the understanding of the implementation process, which can be seen throughout different phases. It mainly provides insights into the interactions that occur in the first and second phases of implementing GLPs, as it explores the interactions that occur during the design and operationalization of GLPs. 


\subsection{Case Report - Becoming Greener Together: A Study of a Shipper and an LSP's Collaborative Efforts to Become Greener}

\subsubsection{Summary of case report}

The point of departure for the case report was the need to empirically study and explore the interactions that occur when implementing GLPs. A shipper and an LSP, from which the shipper procures its transport services, have recently adopted new environmental strategies, in which they both identified interaction with other organizations as being important in order to fulfill these strategies and reach their new environmental goals. The shipper identified transports as one of the major drivers for negative environmental impact, and approached the LSP to find possible solutions and become greener. Simultaneously, the LSP has adopted an environmental goal of becoming fossil free by 2030, and has identified its customers, i.e. shippers, as important organizations to include in its newly adopted environmental strategy. Consequently, the two organizations have jointly started a collaborative project in order to become greener together.

The project includes several participants, representing different roles from both organizations. The different roles all correspond to different functions, including business development, supply chain management, logistics, transportation, and sustainability. Different hierarchies within both organizations are also represented in the project. The collaborative gathering has been hosted by the LSP, which also invited the participants, and all functions have been represented at every gathering. The case report is a summary of the empirical data, mainly gathered through observations during three collaborative gatherings between the two organizations, and one internal workshop held by the shipper.

\subsubsection{Contribution to the thesis}

The case report mainly contributes to understanding and describing GLPs, as many different GLPs are discussed in the early phase of implementation, which is studied in the case report. The case report covers all the included GLPs, as represented in the frame of reference. Some GLPs discussed between the shipper and the LSP are different verities of the same GLP, giving more input for some of the GLPs. For instance, many different solutions to increase the fill rate have been discussed between the organizations, focusing on different types of packages, and also on different types of vehicles and transport management. Thus, the case report makes its main contribution to Research Question 1.

The case report also studies the interactions between different actors and functions within an organization, as well as the interactions between the shipper and the LSP. This gives an understanding of the existence of different interactions, both upstream and downstream, and within organizations. It also gives insights into the interaction between shippers and LSPs, which is often highlighted in the literature as a prerequisite for greening logistics. By exploring the different forms of interaction that occur within and between organizations, an understanding of interactions is gained, which contributes to the second research question. Additionally, as interaction in the first phase of implementation is explored, the case report also contributes to the third research question 


\section{Analysis and discussion}

The analysis and discussion are structured in three sections, which correspond to the three research questions. They build upon the contributions from Paper II, Paper III, and the case report. To clarify which study is being referred to: Study 2 will be called Study on the consolidation center; Study 3 will be called Study on implementing alternative fuel; and Study 4 will be called Study on collaboratively identifying GLPS. Each section in chapter 5, which corresponds to a research question, contains italicized sentences that correspond to the main findings in the analysis for each research question. The chapter is structured in the same order as the research questions.

\subsection{Describing green logistics practices to include the need for interaction}

To describe green logistics practices (GLPs) so that they include the need for interaction, additional knowledge, which can expand the understanding of the GLPs, is gathered from the included studies. Two themes have been identified, motives and organizational level of decision and impact, which are used to describe how GLPs can include interaction. The two themes have been identified as central in the description of the interaction that occurs when implementing GLPs and they are therefore suggested to describe GLPs so that they include the need for interaction. Before going on, the linkage between the studies and the GLPs is presented, followed by an explanation of the two themes that have been identified.

The GLPs that were considered as commonly occurring within the literature were also recurrent in the studies. The GLPs found in the literature are presented in Table 5.1, where the linking between the frame of reference and the study in which the GLPs are explored further can be seen. In the table, lower-case ' $\mathrm{X}$ ' denotes a weak connection, upper-case ' $\mathrm{X}$ ' denotes a strong connection.

Table 5.1. Observed GLPs in appended empirical studies

\begin{tabular}{lccc}
\hline Green logistics practice & $\begin{array}{c}\text { Consolidation } \\
\text { center }\end{array}$ & $\begin{array}{c}\text { Implementing } \\
\text { alternative } \\
\text { fuel }\end{array}$ & $\begin{array}{c}\text { Collaboratively } \\
\text { identifying } \\
\text { GLPs }\end{array}$ \\
& (Paper II) & (Paper III) & (Case Report) \\
\hline Alternative fuel & $\mathbf{x}$ & $\mathbf{X}$ & $\mathbf{X}$ \\
Logistics system design & & & $\mathbf{X}$ \\
Increase fill rates & $\mathbf{X}$ & & $\mathbf{X}$ \\
Modal shift & $\mathbf{x}$ & $\mathbf{x}$ & $\mathbf{X}$ \\
Eco-driving & & & $\mathbf{x}$ \\
Vehicle technology & & & $\mathbf{x}$ \\
\hline
\end{tabular}

Both motives and organizational level of decision and impact can help with understanding which organizations need to be included and interacted with in order for LSPs to implement GLPs. Motives, which is suggested as the first theme, help with understanding which other organizations or actors might have affected the LSP's decision to become greener by implementing GLPs. For instance, shippers can request that LSPs become greener so this can 


\title{
5. Analysis and discussion
}

be used in marketing towards their consumers and to gain a competitive advantage (see e.g. Kumar et al., 2012), or the LSPs themselves might implement GLPs to attract new shippers as customers, or to prepare for an increased demand for green services (Liimatainen et al., 2015). Additionally, internal actors within the LSP organization may also have motives for making the LSP greener, which also adds the dimension of possibilities for internal interaction.

The second suggested theme is organizational level of decision and impact. GLPs can be described at and assigned to certain organizational levels, where decisions on GLPs at higher organizational levels (e.g. strategic) often lead to decisions and possible changes at lower organizational levels (Aronsson \& Huge-Brodin, 2006). For instance, increasing fill rates by implementing a consolidation center affects several organizations in the supply chain, which suggests that the GLP is a decision and a change on a strategic level, which in turn opens up the possibility of tactical or operational decisions and changes for those organizations. However, GLPs that are considered operational decisions can affect other actors or organizations, as exemplified through the study of Anderhofstadt and Spinler (2019), where decisions regarding alternative fuel included e.g. fuel providers (current fuel cost and fueling infrastructure) and vehicle manufacturers (purchasing price, expenses for repairs, and service and maintenance cost). That is why both the organizational level of the decision and the organizational level of the impact should be considered.

\subsubsection{Motives}

As argued above, motives to implement GLPs outline the many actors and organizations with an interest in the LSP becoming greener. To exemplify how motives can describe GLPs so that they include interaction, the motives from the studies to implement GLPs are expanded upon.

\begin{abstract}
Alternative fuel
Alternative fuel is a frequently proposed GLP, represented both in most of the literature (see e.g. McKinnon, 2010; Colicchia et al., 2013; Jazairy, 2020b), but also empirically, as it was represented in all of the studies (see table 5.1). In the studies, the motives for implementing alternative fuel differed. In the study on the consolidation center, it was highlighted that the implementation of another GLP (the consolidation center) led to merged goods volumes from several organizations, enabling collective procurement of HVO100 fuel to acquire better prices. The motives to implement alternative fuel were part of the motives to implement the consolidation center, which are expanded upon below.
\end{abstract}

In the study on implementing alternative fuel, internal drivers and competitive advantage (in line with e.g. Kumar et al., 2012) were found to be the main motives. However, in order to implement alternative fuel, and to maintain at least the same performance and service levels as crude-oil alternatives, a combination of different alternative fuels was implemented. This was done in order to become fossil-free without losing efficiency and to balance the pros and cons that different fuel types offer, in line with e.g. Leonardi et al. (2015), but also to mitigate the varying refueling infrastructure of e.g. LBG compared to HVO (see Anderhofstadt \& Spinler, 2019). Thus, it is equally important to implement alternative fuel with current customers in mind, despite the motive to attract new customers.

In the study on collaboratively identifying GLPs, the motives to study alternative fuel as a potential GLP were both the geographical positions of e.g. the shipper's warehouse and the LSP's closest hub and the short distance, which allows for new technology with untested reliability (Anderhofstadt \& Spinler, 2019), but also the LSP's prior success in implementing 


\section{Analysis and discussion}

alternative fuel with other shippers. Again, it is illustrated that alternative fuel is suggested as a GLP when the motive is to decrease the environmental impact without having major effects on customer service levels. This suggests that implementing alternative fuel is motivated by its simplicity and the fact that it does not affect the service levels offered to current customers.

\section{Logistics system design}

In the study on collaboratively identifying GLPs, the shipper and the LSP identified the longer line-haul transports between the LSP's regional hubs as having the biggest environmental impact in their logistics system. Thus, motives to reduce the impact of these line-haul transports were found at both organizations. As the LSP has an established transport network and the shipper has only one warehouse, the options for a more flexible decentralized solution are limited (see e.g. Martinsen \& Huge-Brodin, 2014). Suggestions in the discussions between the two organizations were to utilize the LSP's hubs as local warehouses and to have some highvolume suppliers deliver to these local warehouses. The motive to increase the number of nodes and links in the system, creating a more decentralized logistics system, comes from reducing the impact of high-capacity links, relieving these links by re-arranging flows, in line with the effects of going from a centralized system to a more decentralized logistics system (see e.g. Martinsen \& Huge-Brodin, 2014). Notably, this would lead to less transport work for both the suppliers and the LSP, potentially reducing their transport costs.

\section{Increase fill rate}

Notably, vehicles could seem to be carrying less than full load, but different factors limit loading possibilities, which also leads to different motives - and ways of increasing fill rates. In the study on collaboratively identifying GLPs, this becomes evident as shipments are consolidated by the LSP to increase utilization (see e.g. Allen et al., 2012). However, these transports accounted for the largest relative negative impact, and fill rates in the vehicles are limited by laws to ensure safe work environments, and by the shipper's usage of standardized loading boxes for their goods. According to the LSP, the vehicles are fully loaded, but at the same time, the shipper's customers are experiencing that their boxes contain "air". Thus, the shipper's motives are to increase the fill rates in the LSP's transports by reducing the air in the boxes, which in turn is requested by the shipper's customers. Reduced air in the boxes would potentially lead to requiring less transports, which would lead to a financial incentive for the LSP. This exemplifies that organizations must consider the environmental demands of their customers (Liimatainen et al., 2015) as the shipper is serving the demand of reducing the air in the boxes from their customers and the LSP is serving the demand of their customer, which is the shipper, of increasing the fill rate. Also, it illustrates that green requirements are transferred upstream in the supply chain (Lee et al., 2014). Thus, interaction is required to capture the motives that other organizations can have, but to capture the motives of organizations further downstream in the supply chain, LSPs must interact directly with these (e.g. shipper's customers) or through the shippers. This suggests that different organizations can have different motives for increasing the fill rate, which can have implications for with whom they need to interact.

In the study on the consolidation center, the motives for using a consolidation center varied with regard to different actors involved. The municipalities stated that using a consolidation center would achieve order in the system, as it would give more control over procurements and shipments, whilst the county administrative board said that environmental performance was the motive. This exemplifies that within organizations (as the county administrative board and the municipalities are considered the same organizations in this thesis), different actors can have different motives. To increase fill rates, many organizations are often involved (see e.g. 
Björklund et al., 2017; Rogerson \& Santén, 2017) with organizations having their motives for increasing the fill rate (as reasoned previously in the paragraph above), but it should be noted that different actors within these organizations also have different motives, and that these actors need to be considered as well. That is why this thesis suggests that that different actors within organizations can have different motives for increasing the fill rate.

\section{Modal shift}

In the study on collaboratively identifying GLPs, motives to reduce the impact of the line-haul transports, including sending shipments by different transport modes, were discussed. This resulted in a proposal for intermodal solutions using trains. In the literature, it is suggested that modal shifts become a trade-off between e.g. lead-time and flexibility (see e.g. Eng-Larsson \& Norrman, 2014). However, in the study on collaboratively identifying GLPs, the shipper used weekly deliveries, a solution where customers, regardless of when they ordered, receive shipments on a given day. This facilitates the use, for example, of rail services, as it enables better planning and gives room for the longer lead-times required for e.g. re-routing, and additional nodes in the transport system. Thus, modal shift was motivated by its ability to be implemented without compromising the service level currently offered to customers, and by extension, lead to improved environmental performance and reduced costs for the LSP and the shipper. This suggests that motives to use other transport modes are based on the effects of other transport modes on lead-times and service levels.

\section{Eco-driving}

Despite not being represented as a GLP in the studies, eco-driving is now a well-established practice amongst LSPs. In the studies, eco-driving was already practiced by the LSP's drivers and thus not discussed as a GLP to be implemented. This might be due to an EU directive that requires all operators of heavy goods vehicles, in all EEA member states, to undergo recurring training, including in eco-driving, every five years. However, as the motives for driving in a cost and environmentally efficient way are to reduce the impact and costs of transports, they align with motives to implement other GLPs. Training and follow-up are highlighted by e.g. Huang et al. (2018) as amplifying the effects of eco-driving, and with the addition of advancing technology, the support for drivers will continue to improve the effects of eco-driving. Thus, no motives to implement eco-driving were found in the studies, because all LSPs claimed to already practice eco-driving. This separates eco-driving from other GLPs, as it is in the interest of many that LSPs practice eco-driving, but no motives behind why it is to be practiced or implemented can be found, other than compliance with the legislation (e.g. regulatory pressures, see Liimatainen et al., 2015). This thesis identifies that motives for implementing eco-driving are mainly driven by legislation.

\section{Vehicle technology}

The motives to implement vehicle technology were, in all cases, aligned with or part of the implementation of other GLPs. When implementing alternative fuel in the study on implementing alternative fuel, vehicle technology was utilized to be able to implement liquefied biogas (in line with e.g. Björklund et al., 2016), which at the time was a relative new technology in Sweden. Similar claims can be made for the study on collaboratively identifying GLPs and the different technologies suggested between the shipper and the LSP, where the main motives were either to increase fill rates using technology, or to move transports onto electrified solutions; motives that were shared by both organizations. Thus, no additional input can be found for vehicle technology, as the previously investigated GLPs covered the motives for implementing vehicle technology as well. This strengthens the findings of e.g. Aronsson and Huge-Brodin (2006), that GLPs are interrelated and affect each other. 


\section{Motives as a mean to include interaction in the description of GLPs}

To conclude how motives can expand the understanding of GLPs, and describe how GLPs can include interaction, generalized findings from the GLPs are discussed. One recurring motive is that GLPs are suggested based on their fit into the current logistics system, and that motives to become greener are steered by the possibility of making the logistics greener, without affecting the service levels in the system, in line with the definition of green logistics by Wu and Dunn (1995) that green logistics should not affect logistical efficiency. This is exemplified in the way many of the studied GLPs are designed so that they will not negatively impact the efficiency of the current logistics system. For instance, the rail solution (modal shift) in the study on collaboratively identifying GLPs was only viable because the system allowed longer lead times that did not affect customer service levels. Similarly, alternative fuel was suggested in the same study as it fitted into the current logistics system, without compromising the service levels or efficiency in the system. This was also evident in the study on implementing alternative fuel, where the combination of different alternative fuels allowed for a fossil free fleet which could perform similarly to a crude-oil based fleet. This finding illustrates that the GLPs are implemented with regard for current customers and suppliers, and that motives for the LSP to implement GLPs are found within the LSP, the shipper, and the shipper's customers. However, as illustrated in the study on implementing alternative fuel, other organizations, such as fuel providers and vehicle manufacturers, also have an interest in the LSP choosing their technology and could therefore interact with the LSP to "persuade" them into choosing their technology. That is why this thesis proposes that motives to implement GLPs are foremostly based on the possibility of greening logistics, without losing operative efficiency and affecting the customer service levels in the logistics system, and that different organizations have different motives for and interest in the LSP becoming greener.

Another finding suggests that different actors within organizations might have different motives for implementing GLPs. This indicates that, in addition to other organizations having different motives for and interest in the LSP becoming greener, different actors within the organizations may have different motives as to why the LSP should implement GLPs. For instance, in the study on collaboratively identifying GLPs, both organizations have dedicated different actors that correspond to different functions within both organizations. The LSP has dedicated e.g. actors that mainly have an interest in serving their customer (i.e. the shipper), who are driven by motives to meet customer requirements (in line with Liimatainen et al., 2015), actors that are driven by motives to improve the LSP's competitive advantage (Kumar et al., 2012), and actors that mainly have an interest in improving the environmental performance to meet future legislation (Liimatainen et al., 2015). This can also be found within the study on the consolidation center, where different actors had different motives as to why the consolidation center should be implemented. This suggests that different actors within organizations have different motives for and interest in the LSP becoming greener.

\subsubsection{Organizational level of decision and impact}

In addition to motives, it is also argued that organizational level of decision and impact is able to expand how GLPs can be described to include the need for interaction. In a similar way to motives, the GLPs from the studies are investigated for the proposed theme below.

\footnotetext{
Alternative fuel

Both in the study on the consolidation center and the study on implementing alternative fuel, the implementation of alternative fuel was initiated from the same organization that intended to implement the GLP (i.e. no pressures or demands from other organizations), and in both studies,
} 


\section{Analysis and discussion}

it was considered to only affect the operational decision level. Implementing alternative fuel can be seen as an operational GLP, where the decision to use an alternative fuel depends on associated costs (Anderhofstadt \& Spinler, 2019), which to some extent is supported by the studies. However, as discussed and concluded in Paper III (study on implementing alternative fuel), the implementation of the GLP alternative fuel often requires the involvement of other functions within the organization, but also other organizations, to be fully implemented. For instance, when implementing alternative fuel to form the fossil free fleet, the implementation of liquified biogas required support from senior management, training drivers in new processes of refueling, applying for subsidies to account for the increased cost of the new technology, and lending demo-vehicles to ensure that the fuel technology was reliable. This indicates that implementing alternative fuel, in fact, may be a tactical or even strategic decision, compared to the original expected operational level, based on the interaction that occurred.

In the study on the consolidation center, the implementation of alternative fuel was enabled by the implementation of the consolidation center, which is considered as a strategic level decision. As presented by Aronsson and Huge-Brodin (2006), decisions at higher organizational levels often enable decisions at lower levels, e.g. the operational level. This is evident in the study on the consolidation center, where the consolidation center enabled the municipalities to merge their goods volumes, which in turn enabled them to procure fossil free fuel alternatives. Thus, the strategic decision to implement the consolidation center enabled tactical decisions of merged goods volumes, which in turn enabled the implementation of alternative fuel. As the interaction occurred primarily to implement the consolidation centers, it can be suggested that interaction to implement GLPS at one organizational decision level can facilitate the implementation of additional GLPs, without additional interaction.

For the study on collaboratively identifying GLPs, the project is still in a phase where potential GLPs are identified, but as the project team consists of members from both the LSP and the shipper, as well as different members from different functions within these organizations, it can exemplify the way alternative fuel impacts a grander organizational decision level, as many different actors corresponding to different functions are concerned with the design of the GLP. This concludes that the organizational level of decision and impact for alternative fuel varies with regard to the specific organization. To implement alternative fuel, organizations, and in particular LSPs, can be required to interact with other organizations and internally within the organization. This suggests that interaction to implement alternative fuel occurs at a different organizational decision level than the GLP alternative fuel impacts.

\section{Logistics system design}

The proposed GLP, to alter the logistics system of the shipper and the LSP in the study on collaboratively identifying GLPs, is proposed to have an impact on the strategical organizational levels, which in turn will affect other organizational levels (Aronsson \& HugeBrodin, 2006). Changing the structure of the supply chain, which the discussed solution would require, would also mean that supplying organizations, the LSP, and the shipper would have to operate and plan their internal operations differently. This can be seen in the study on collaboratively identifying GLPs, where discussions regarding decentralization would require the shipper to alter some of its current processes, whilst the suppliers and the LSP would have to adopt new processes. Thus, strategic organizational level decisions and impacts also affect the lower level of the organizational change hierarchy, but changes are also required at these lower levels. This suggests that altering the logistics system design, which is a higher-level organizational decision, also encompasses decisions at lower levels, which can require interaction at lower levels also. 


\section{Increase fill rate}

Increasing fill rates is a generalized description of different GLPs that, depending on the unit of analysis, aim to increase the utilization and fill rates of a transport system, or individual transports. Naturally, this affects the organizational decision level concerned, depending on what measures are used to increase the fill rate (see e.g. Aronsson \& Huge-Brodin, 2006). In the study on the consolidation center, the implementation of a consolidation center occurs on a strategic level, suggesting that the purpose of the GLP is to increase the fill rates in the perspective of the transport system (in line with e.g. Björklund et al., 2017). Additionally, new physical and organizational structures were required for this GLP to be implemented, which again supports the view that higher organizational level decisions require changes and decisions at lower organizational levels. However, as the purpose of the consolidation center was to increase the fill rate in the logistics system, more interaction is required to measure the performance of the GLP, to establish its successful implementation.

In the study on collaboratively identifying GLPs, the shipper wanted to implement GLPs to increase the fill rates on the transports between its warehouse and the shipper's hub, but also GLPs to increase the fill rates in the shipper's line-haul transports. This illustrates varieties of the GLP to increase the fill rate at different organizational levels, as GLPs targeting increases in the fill rate in standardized packaging boxes are an operational decision, whilst GLPs regarding control of goods flows between markets are tactical decisions (in line with classifications by e.g. Aronsson \& Huge-Brodin, 2006). This illustrates that lower organizational decision levels can also enable organizational decisions at higher levels. For instance, as seen in the study on collaboratively identifying GLPs, reducing the "air" in the boxes would lead to more boxes fitting in the vehicles, which leads to a reduction in the number of transports required to fulfill the transport need, which by extension requires transport management to ensure high fill rates. Thus, it is suggested that the implementation of GLPs that are operational level decisions can enable implementation of GLPS at higher decision levels.

\section{Modal shift}

In the study on collaboratively identifying GLPs, modal shift would be a strategical organizational level decision, as additional nodes will be inserted into the transport system, similar to logistics system design. Additionally, the shipper's investigation of offering rail services concluded that the shipper could either purchase capacity from other LSPs offering rail services, or participate in the extensive process that is Swedish railway planning, to be able to offer rail services themselves. Regardless, both the shipper and the LSP would be affected (see e.g. Lammgård, 2012) as intermodal solutions by rail would affect the current physical structure of the supply chain.

\section{Eco-driving}

Despite being described as an operative GLP, eco-driving requires planning to be implemented, but also to some extent operated. As eco-driving mainly concerns the choices of the driver before, during, and even after driving (e.g. maintenance as proposed by McKinnon, 2010), the impact of eco-driving is mainly operational. No contradictory evidence or findings in the studies could illustrate anything else.

\section{Vehicle technology}

In a similar way to the reasoning for vehicle technology under motives, the GLP is strongly interrelated with other GLPs within the appended studies. Thus, the organizational level of decision and impact is decided by the main GLP that includes vehicle technology. 


\section{Analysis and discussion}

Organizational level of decision and impact as a means to include interaction in the description of GLPs

To conclude, the findings from investigating each GLP presented above will be expanded upon. First, it is evident from the above discussions that it is difficult to determine what organizational decision level will be impacted by decisions to implement GLPs. As illustrated, decisions considered to be e.g. operational can be decisions that concern a higher organizational level. For instance, implementing alternative fuel can be operational, depending on the technology that is chosen, but can also be tactical or even strategic if the LSP is required to interact with many other organizations in order to implement the GLP. Aronsson and Huge-Brodin (2006) conclude that the levels of organizational decision-making interrelate to one another, where decisions at different levels affect decisions at other levels, as supported by this thesis. However, it should be added that this interrelation also makes it difficult to decide which level in the organizational decision hierarchy a particular GLP is assigned to.

The findings suggest that the organizational decision level of a GLP is affected by the interaction that is required to implement the GLP. For instance, in the study on the consolidation center, the LSP was able to implement fossil free alternatives because of the interaction that occurred to implement the consolidation center, and the implementation of alternative fuel was thus an operational decision. In the study on implementing alternative fuel however, the fuel provider, the shippers, senior management, and the drivers had to be interacted with before the GLP could be implemented, suggesting that the implementation of alternative fuel was a decision at a higher organizational level in that specific context, because of the interactions that occurred. This illustrates that the organizational decision level impacted by a GLP can be investigated through the perspective of interactions, to explore how major the impact of the implementation of the GLP will be. That is why this thesis proposes that the organizational decision level for GLPS can be complemented by what other organizations or actors the LSP needs to interact with to implement the GLP.

\subsection{What forms of interactions occur in the implementation of GLPs}

Previously, it was suggested how motives and organizational level of decision and impact include the need for interaction when describing GLPs. As the answer to Research Question 1 has laid the foundation for interaction by describing GLPs to include the need for interaction and illustrated the need to include other organizations or actors, the next step is to investigate the forms of interaction that occur when implementing GLPs. To answer the second research question, exploring what forms of interaction occur in the implementation of GLPs, the analysis and discussion follow three steps. First, the interactions are identified (5.2.1), then the content of the interactions is explored using the parameters sharing information, transferring knowledge, sharing resources, and communication (5.2.2), and lastly, this thesis explores the form of the interactions (e.g. arm's-length, collaborative, or on the scale in-between) (5.2.3).

The first step is to identify the interactions that were formed in the implementation, and to map the organizations that were interacted with. Additionally, organizations mentioned within the studies are also identified, but as no interaction with these organizations could be identified, no links with these organizations are shown. 


\section{Analysis and discussion}

\subsubsection{Identified interactions and organizations}

In the different studies, different purposes have resulted in different ways of acknowledging and addressing interaction, organizations, and actors. Thus, the first step is to identify the organizations, actors, and interactions that occur, in a similar way as was done for the study on implementing alternative fuel, which has come furthest in this regard. That is why this chapter starts by summarizing the interactions, organizations, and actors that were already identified in the study on implementing alternative fuel, to use the same structure and logic for the study on the consolidation center, and the study on collaboratively identifying GLPs. Denominators and differences between the studies are presented at the end of this chapter.

\section{Study on implementing alternative fuel}

In the study, where the GLP alternative fuel was implemented in a vehicle fleet, two internal interactions and five external interactions were identified as occurring during the implementation of alternative fuel, and specifically LBG fuel. A figure depicting the interactions formed and the actors involved is presented below (Figure 5.1), where interactions between organizations inside the green field represent internal interactions. The study shows that internal interaction occurs between the LSP, a haulage operator that is owned by the LSP, and drivers. The structure of the LSP means that the haulage operator is owned by the LSP but is operated individually, with its own management. The haulage operator, in turn, has a clear distinction between management and operative personnel (e.g. drivers), creating additional internal interactions. The internal interaction between the haulage operator and the drivers centers around daily operations. Thus, the LSP's organization consists of three tiers, as encompassed in the green box. Three of the external interactions in the case occurred between an LBG fuel provider and the LSP, the haulage operator, and the drivers. Additionally, two external interactions between the haulage operator and the shippers, as well as the 2nd tier shippers, also occurred. Other organizations were mentioned within the case, e.g. vehicle manufacturers and one subsidizer, but no interaction occurred with these organizations.

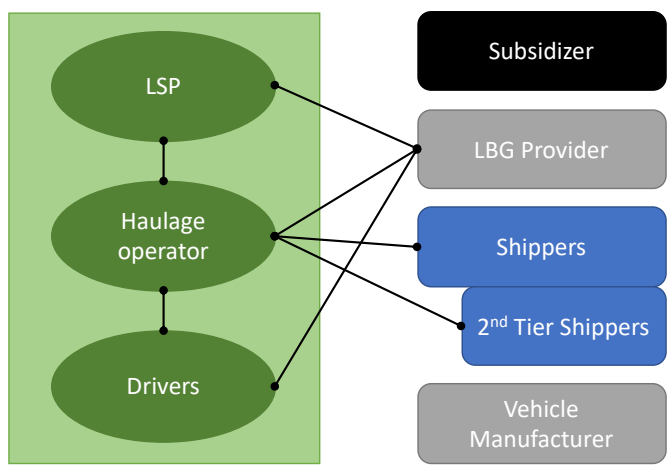

Figure 5.1 Interaction to implement alternative fuel, from Paper III

\section{Study on the consolidation center}

For the study on the consolidation center, a similar analysis established that one internal interaction and six external interactions occurred. Figure 5.2 depicts the interactions that occurred in the study, subject to the measurement that is being studied in the case. Based on the empirical description of the case presented, internal interaction occurs between the county administrative board and the municipalities. The county administrative board is superior to the municipalities and normally separate, but in the studied case the county administrative board 


\section{Analysis and discussion}

managed the municipalities. Also, the county administrative board has access to certain resources (e.g. applying for funds), which the municipalities can only access through interaction. Additionally, external interaction occurs between the municipalities and the LSP, where the LSP was procured to operate the consolidation center and the shipments between the consolidation center and the receiving units. External interaction also occurs between the municipalities and the receiving units. The external interaction between the municipalities and the receiving units is special, because the municipalities own the receiving units, which consist of e.g. schools and offices. Regardless, these interactions are external as no connection except for the ownership structure links the two types of organizations together. Lastly, the external interactions that occur between the research institute and the other organizations exist in order to conduct the performance measurement of the consolidation center. In a similar way to the case of implementing alternative fuel, additional organizations were mentioned, but no interaction with these organizations could be identified. For instance, a subsidizer was mentioned, but no interaction was identified, except for an application for funds to perform the measurement.

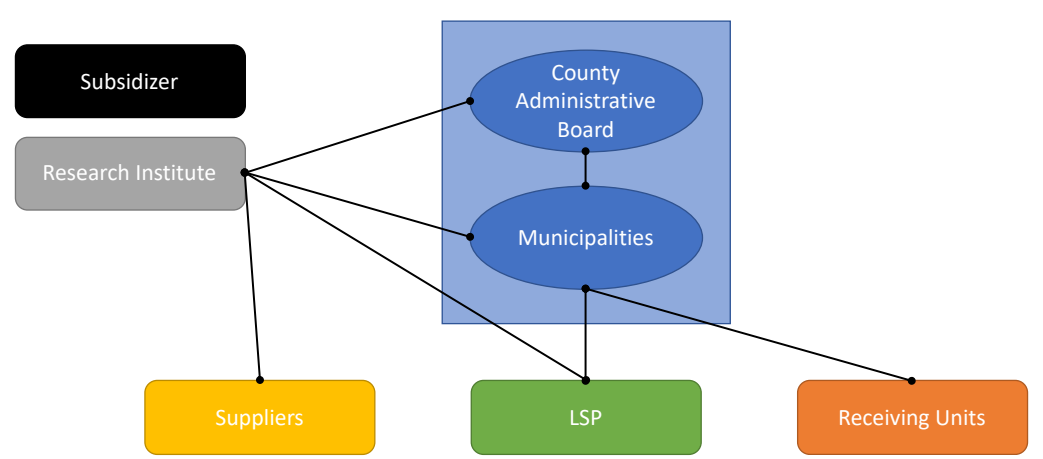

Figure 5.2 Interaction to implement a municipal consolidation center, from Paper II

\section{Study on collaboratively identifying GLPs}

The analysis of the interactions in the study on collaboratively identifying GLPs differs from the previous two studies. In the study, the shipper and the LSP have just recently initiated their joint efforts to become greener. It concludes that one definite external interaction currently exists between the shipper and the LSP. However, in the early stage of interaction between the two, several GLPs were discussed that explicitly target other supply chain organizations, thus requiring interaction to some extent. GLPs that depend on technology providers or technology enablers were discussed and would, depending on the concrete GLP, require external interaction. This interaction would occur either between the shipper or the LSP, and the technology provider. Furthermore, different alternatives of logistics system designs were discussed by both organizations, which would require the shipper to interact with either its suppliers or customers. For instance, the shipper suggested GLPs that would steer goods past its own warehouse, directly to its customers. Similarly, solutions where returns are delivered directly to the suppliers were discussed. Additionally, both organizations included different functions within their respective company, which suggests that internal interaction occurs, but has not yet been observed in relation to specific GLPs. The tentative interactions depend on which GLPs the organizations proceed with and thus the interactions are left out from the figure. The external interaction between the shipper and the LSP is, however, depicted as a solid line. Note that no internal interactions are depicted in the figure. 


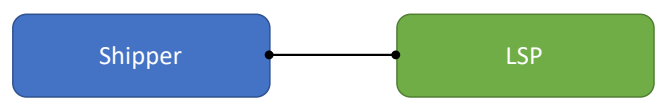

Figure 5.3 Interaction to collaboratively identify GLPs, from case report

\section{Identified interactions and organizations}

Despite being different GLPs that are applied in different setting, some traits recur within the studies presented above. The LSP and the shipper are represented in all of the studies and the interaction between shippers and LSPs is often highlighted in the literature as crucial in order to implement GLPs (see e.g. Evangelista, 2014; Evangelista et al., 2018). This can be observed in the study on collaboratively identifying GLPs, as the interaction between the shipper and the LSP is the only interaction that can be identified early in the implementation process. In the study on the consolidation center, the shipper is represented by the municipalities as the receiving units, but also the organizations managing the goods flows, i.e. the organizations that require goods to be shipped. Additionally, in the study on implementing alternative fuel, the LSP is represented not only as the LSP, but also as a haulage operator, and its drivers, together with the shippers and the 2nd tier shippers. This suggests that interaction between Shippers and LSPs is central for the implementation of GLPS.

Several papers in the literature on GLPs that focus on interactions have acknowledged the need for a wider perspective than a single firm perspective and most studies focus on the shipperLSP interaction from different perspectives. This is also evident in the results from Paper I, where most studies are limited to a single-firm or dyadic perspective. However, more interactions occur, which requires a wider scope to capture all the perspectives and interactions. As evident in the studies presented above, other interactions with additional organizations are also identified and can to some extent be as important. The study on implementing alternative fuel showed that the fuel provider had an important role in the implementation of alternative fuel, compared to e.g. the vehicle provider, with whom no interaction could be identified. Similarly, in the study on the consolidation center, the performance measurement, concluding the consolidation center as a successful GLP, was enabled by the interaction between a research institute and the other organizations. This suggests that interaction with organizations other than shippers is also important when LSPs implement GLPS.

Notably, in the presented studies, internal interaction is also observed. Internal interaction is suggested as a prerequisite for external interaction (Stank et al., 2001), and in both the study on the consolidation center and the study on collaboratively identifying GLPs, internal interaction led to external interaction for the GLPs. For instance, in the study on collaboratively identifying GLPs, several functions within the organizations interacted both with functions within the same organizations and with other functions at the other organizations. In Paper I, one of the findings suggested that internal actors have different experiences of interaction, and as external interaction is the product of internal interaction, it can be suggested that internal interaction 


\section{Analysis and discussion}

affects the external interactions. The interaction between functions other than logistics (both internally and externally) is necessary in order to achieve collaboration (Bowersox, 1992), and collaborative interaction is highlighted as a facilitator for green logistics (see e.g. Touboulic \& Walker, 2015a). This suggests that internal interaction is important when implementing GLPs.

Furthermore, in the study on the consolidation center, the county administrative board managed and synced the overall strategical environmental goals with the operations of the municipalities, supporting the municipalities in adapting and evaluating the consolidation center. Similarly, in the study on collaboratively identifying GLPs, internal interaction between senior management and logistics functions supports the conclusion that time, information, and knowledge are spent on the external interactions to green the current operations of both organizations. Furthermore, lower hierarchical groups in organizations (e.g. drivers) also need to be included in the implementation. In the study on implementing alternative fuel, the LBG provider claimed that the drivers must be acknowledged and included in the implementation process to ensure a problem-free implementation. For instance, when the haulage operator operationalized LBG vehicles, some drivers refused to drive such vehicles, both because of the type of fuel, but also the change to the brand of the vehicles. This summed up how internal interaction enables the inclusion of actors within the organizations when implementing GLPs. It is suggested that internal interaction is a necessity to form the external interactions to implement GLPS.

\subsubsection{What constitutes the interactions}

Following the identification of interactions and organizations, the next step is to explore what constitutes the interactions. This exploration is based on the parameters identified and presented in the frame of reference to assess the form of the interaction, where interaction between two organizations is described in terms of sharing information, transferring knowledge, communication, and sharing resources (in line with e.g. Bowersox, 1992; Spekman et al., 1998; Soosay et al., 2008). Two additional parameters are also used to explore the interactions, trust and commitment (suggested by e.g. Touboulic \& Walker, 2015a), but are expressed through the other parameters. For instance, by sharing a certain type of information, one organization trusts the other, or by transferring knowledge or sharing certain resources, the organization is committing to the other. The first four presented parameters are explored respectively for the presented studies below, with references to the additional two parameters.

\section{Sharing information}

Sharing information is considered one prerequisite for interaction (Dyer \& Singh, 1998; Spekman et al., 1998). Sharing information can be found in all of the presented studies, with varying intensity and importance of the information. For instance, in both the study on collaboratively identifying GLPs, and in the study on implementing alternative fuel, information regarding fleet design and shipping capabilities was openly shared between the LSPs and the shippers. This type of information can be sensitive, in terms of e.g. negotiations and for the shipper to leverage other LSPs, as fleet design is one basis of competition for LSPs, which suggests a certain level of trust. Other examples of information sharing can be seen in the study on collaboratively identifying GLPs, where both organizations openly shared information regarding upcoming internal strategical goals and changed operations to synchronize the GLPs to this information. In the study on the consolidation center, once the performance measurement of the consolidation center was initiated, the research institute gained access to data. As the data were sensitive, the LSP required the research institute to sign a confidentiality agreement, which illustrates the absence of trust. Findings illustrated that in all of the studies, information was generally shared openly between organizations, despite the 


\section{Analysis and discussion}

potential for such information to be used for other purposes by the organizations. This suggests that sharing information with varying intensity and importance is central for interaction to implement GLPS.

\section{Transferring knowledge}

In addition to sharing information openly within the studies, transferring knowledge is also a recurring feature in several of the interactions. Transferring knowledge, compared to information sharing, is about transferring learnings or experiences across to the other organization or actors, and can be seen as a measure of commitment (see e.g. Touboulic \& Walker, 2015a). In the study on the consolidation center, the municipalities transferred knowledge between each other about a new procurement system, required for the consolidation center to function. In the study on collaboratively identifying GLPs, the shipper had to transfer knowledge to the LSP about their flow of goods, not only from the warehouse to the customers which the LSP was operating. Similar findings can be seen in the study on implementing alternative fuel, where the LBG fuel provider transferred knowledge regarding the technology and its associated processes to the LSP, the haulage operator, and the drivers. For the studies, it was found that knowledge transfer occurred between the LSP and other organizations, but on all occasions, the LSP was in receipt of knowledge. This suggests that LSPs can absorb knowledge from other actors and organizations to gain an increased understanding of the parts of the system and to be able to implement GLPs successfully.

\section{Communication}

Information sharing and knowledge transfer are mediated via different types of communication. Communication is highlighted by the literature as a prerequisite for any form of interaction (see e.g. Bowersox, 1992), and can be classified by frequency and formality. The studies contain formal, infrequent communication, as found in the study on the consolidation center between the research institute and the other organizations, and in the study on implementing alternative fuel between the haulage operator and the 2nd tier shippers. Typically, this type of communication consists of scheduled singular meetings with a predetermined agenda and purpose, email correspondence, or similar. Additionally, within the studies, formal and frequent communication occurs, which is exemplified by the interaction between the LSP and the haulage operator in the study on implementing alternative fuel, during regular meetings, or reporting on progress, etc. In the study on implementing alternative fuel, informal communication occurred between the haulage operator and the shippers, in what was described as discussions, but also characterizes the communication between the shipper and the LSP in the study on collaboratively identifying GLPs, in workshops where discussions are open to all participants. However, some communication e.g. email conversations or similar types of communication can be difficult to classify, and at the same time, "face-to-face" communication can also be affected by e.g. personal bonds or opinions of the participants. This suggests that communication is vital in order to share information and transfer knowledge and is central for the interaction to implement GLPs.

\section{Sharing resources}

An additional type of interaction found in the studies is sharing resources. In the literature, larger resource pools are considered one effect of interacting more collaboratively (Soosay et al., 2008), but in order to increase the resource pools, organizations need to add resources to that pool, and thus share their resources. Resources can be information and knowledge, but also include physical assets, financial funds, or time. For instance, investing in the interaction (see e.g. Bowersox, 1992) is one way of expanding the resource pool and sharing those resources. This is illustrated in the study on implementing alternative fuel, where the LSP provided 


\section{Analysis and discussion}

funding for the haulage operator to update the fleet, thus sharing economic resources. In the same study, the LBG fuel provider also offered demo-vehicles for the haulage operator to try, before purchasing their own vehicles, and therefore shared physical resources (e.g. vehicles). In the study on collaboratively identifying GLPs, both organizations currently share resources in terms of time, but have also discussed GLPs that would require investments and thus economic resources. In the study on the consolidation center, no resource sharing can be found in the identified interaction. For instance, the services of the LSP are procured and no resources were inserted into the interaction. Thus, resource sharing must benefit the interaction, and must be able to be accessed by both organizations to be considered as sharing resources. This suggests that sharing resources is a central part of interaction to implement GLPS.

\section{What the interactions consist of}

Interactions consist of many different parameters, as investigated above. Thus, to implement GLPs, LSPs must interact in different ways. It has been illustrated that all of the presented parameters are covered by the interactions identified in the different studies. This in turn highlights that interactions can consist of different content. For instance, some interaction occurred to gain resources, whilst other interaction occurred to acquire knowledge. In all the identified interactions several parameters have been found within the interactions. The parameters trust and commitment are experienced through other parameters, where trust was often found within information sharing. Interactions are in one sense versatile, as they include several parameters, and that interaction with other actors or organizations can be beneficial for both parties. This can also support the identification of absent interactions, despite an organization being mentioned by other actors or organizations, as the exchanges with these organizations are brief and not versatile. For instance, when purchasing a vehicle, both organizations exchange resources (financial means for the vehicle). This thesis identifies that trust is associated with sharing information, when interacting to implement GLPS.

As information sharing was apparent in all studies, and in most interactions, it is suggested that when interacting, information is primarily used to acquire resources, knowledge, or additional information. For instance, in the study on the consolidation center, information was shared with the research institute in the form of data, which could produce learnings or experiences that were then shared with the other organizations as knowledge. This knowledge, in turn, was used to assure politicians of the success of the consolidation center, which enabled continuous funding for the consolidation center. However, it was also found that organizations often share information freely, without considering what the recipient uses the information for. This thesis proposes that information sharing is used to gain access to additional information, knowledge, or resources when interacting to implement GLPS.

\subsubsection{The forms of interaction}

The third and final step of the analysis for RQ2, is to assess what form, e.g. where on the scale between arm's-length and collaboration, the interactions are positioned, and thus what form they take. Based on the literature, it is suggested that if an interaction consists of informal, frequent communication (Bowersox, 1992) with knowledge transfer and information sharing, high levels of trust (Touboulic \& Walker, 2015a), investments in the interaction (Dyer \& Singh, 1998), and sharing resources (Soosay et al., 2008), the interaction is suggested to be collaboration. However, if the information sharing consists of formal, infrequent communication (Bowersox, 1992), lacking knowledge transfer and trust, the interaction can be classified as an arm's-length interaction, or somewhere in between the extremes. Both arm's- 


\section{Analysis and discussion}

length and collaboration, as well as interactions in between the extremes, have been identified within the studies and are expanded upon below.

All in all, many findings from the studies indicate that collaborative interactions have been formed in order to implement GLPs, something also claimed as a requirement in the literature (see e.g. Liimatainen et al., 2015; Evangelista et al., 2018). For instance, collaboration between shippers and LSPs has been found within all studies, as well as inter-organizational collaboration, between actors within organizations, as exemplified in the study on implementing alternative fuel, between senior management and the haulage operator, and in the study on collaboratively identifying GLPs between actors in both organizations. In the study implementing alternative fuel, the interaction with the fuel provider was also collaborative, with high levels of trust, knowledge transfer, resource commitment, and intensive communication between the organizations. This suggests that collaboration between LSPs and shippers is central for the implementation of GLPS.

However, in the studies, arm's-length interaction also occurs, and in some instances is as important as collaborative interactions. This is exemplified by the interactions formed between the research institute and the other organizations in the study on the consolidation center, where brief and short information exchanges with high levels of trust enabled the evaluation that confirmed the consolidation center as an improvement for environmental performance, and by extension, the factor that qualified the consolidation center as a permanent logistics practice. Similarly, in the study on implementing alternative fuel, internal interaction, in arm's-length form, was necessary to include the drivers in the implementation and to ensure a successful transition. Thus, collaboration may be a facilitator for implementing GLPs (Carter \& Rogers, 2008), especially between LSPs and shippers, although findings from the studies also suggest that lesser forms of interaction are required. This suggests that more arm's-length forms of interaction between LSPS and other organizations and actors are important for LSPS to implement GLPS.

\subsection{The characteristics of interaction in different phases of implementing GLPs}

The implementation of GLPs is a process that progresses over time and it is suggested that this process can be seen from different phases. To answer the third research question, and decide what phases constitute the implementation process, and how the interactions change during the process, interactions that have previously been examined from the studies will be further explored throughout the process, followed by summarizing how the different phases characterize the interaction that occurs in the phases. This is in line with the research agenda, presented in Paper I, where interaction should be studied over time to explore how interaction can evolve or unfold.

In the frame of reference, it has been suggested that different phases constitute the implementation process, which has been identified within the appended studies. These phases are identifying needs and designing GLPs, operationalization of GLPS, and lastly follow-up. In these phases, the interactions that were previously explored in RQ2 will be investigated to find out how interaction might change with regard to the implementation process, and to explore how the interactions can be characterized by the three phases. 


\section{Analysis and discussion}

The appended empirical studies have different focuses on the different phases suggested. These focuses are described in Table 5.2, and it is illustrated that the identified phases are covered in the appended empirical data. The phases are expanded upon below.

Table 5.2. The phases found in the literature on which the empirical studies focus

\begin{tabular}{llll}
\hline Study & $\begin{array}{l}\text { Identifying needs and } \\
\text { designing GLPs }\end{array}$ & $\begin{array}{l}\text { Operationalization of } \\
\text { GLPs }\end{array}$ & Follow-up \\
\hline $\begin{array}{l}\text { Consolidation } \\
\text { center } \\
\text { (Paper II) }\end{array}$ & $\begin{array}{l}\text { Additional insight on the } \\
\text { operationalization of the } \\
\text { consolidation center. }\end{array}$ & $\begin{array}{l}\text { Main focus was } \\
\text { performance measurement } \\
\text { of a consolidation center. }\end{array}$ \\
$\begin{array}{l}\text { Implementing } \\
\text { alternative fuel } \\
\text { (Paper III) }\end{array}$ & $\begin{array}{l}\text { Additional insights on the } \\
\text { design of the GLP and to } \\
\text { some extent the } \\
\text { identification of needs. }\end{array}$ & $\begin{array}{l}\text { Main focus was the } \\
\text { implementation of } \\
\text { alternative fuel by a } \\
\text { haulage operator. }\end{array}$ & \\
$\begin{array}{l}\text { Collaboratively } \\
\text { identifying }\end{array}$ & $\begin{array}{l}\text { Main focus was the } \\
\text { collaborative efforts to } \\
\text { GLPs }\end{array}$ & $\begin{array}{l}\text { generate and form GLPs } \\
\text { to implement. }\end{array}$ & \\
(Case Report) & & & \\
\hline
\end{tabular}

\subsubsection{Interaction throughout the different phases}

\section{Identifying needs and designing GLPs}

The first phase of the implementation process is two-fold: first, to identify the need to become greener, and second, to design the GLP that aims to fulfill that need. The first phase was mainly examined in the study on collaboratively identifying GLPs, but the study on implementing alternative fuel also gave insights to this phase. The identification of needs is closely interrelated to motives, as presented in chapter 5.1.1. The interaction that occurs to identify the motives for the LSP to become greener thus occurs in the first phase.

The inclusion of customers in the early phases of implementation is also suggested in the literature (e.g. Flint et al., 2005; da Mota Pedrosa, 2012), and is found in two of the appended studies. In the study on collaboratively identifying GLPs, this is evident as the LSP and the shipper (i.e. customer to the LSP) jointly participate in the identification of needs (and motives) but have also started to design GLPs. As this process is iterative, where the design may require the organizations to go back to their motives, it is difficult to separate the interactions that occur for identifying needs from the designing of the GLPs, and it is suggested that they should constitute one phase. The interaction that occurs between the shipper and the LSP in the study on collaboratively identifying GLPs thus becomes the interaction for both identifying needs and designing the GLPs. The form of interaction is collaborative, due to high levels of commitment, trust, and information sharing - both between the organizations and internally within each organization. Close forms of interaction early on in the process have enabled shorter processes when it comes to suggesting and designing GLPs, as both organizations, as experts within their own fields, have been able to jointly produce feasible and potentially efficient GLPs. 
In a similar way to the study on collaboratively identifying GLPs, in the study on implementing alternative fuel, the largest shippers of the haulage operator were invited to help find a composition of vehicles operating on alternative fuels that would ensure a fossil free fleet, without losing efficiency or greatly increasing the costs for the customers. In this study, it was concluded that the main motive to implement alternative fuel was the internal drive of the site manager of the haulage operator. Thus, no interaction could be identified in the identification of needs, despite others having motives for the haulage operator to implement the GLP alternative fuel. With the shippers sharing their financial resource pool, and agreeing to sign long-term contracts, the haulage operator and the shippers jointly designed the GLP alternative fuel which, based on the parameters that the interaction consisted of, suggests that a deeper form of interaction occurred between the two organizations. This indicates that deeper forms of interaction between the LSP, or the extension of the LSP, the haulage operator, and the shipper, is important in the early phases of implementation. Thus, this thesis proposes that more collaborative forms of interaction between LSPs and shippers are important for identifying and designing GLPs.

However, in the study on implementing alternative fuel, additional interactions proved important for the implementation. The interaction between the LBG fuel provider and both the LSP and the haulage operator is characterized by information sharing, frequent communication and knowledge transfer, suggesting that these interactions were more collaborative than arm'slength, but also important for the inclusion of LBG vehicles and therefore the design of the fleet. This indicates that other supply chain organizations need to be included, like the way that the fuel provider was included in the design of the fleet (in line with e.g. Björklund \& Forslund, 2018), in the early phases of interaction. Apart from external interactions, the internal interaction between the LSP and the haulage operator also proved important, as it was in this interface that resource allocation, synchronization of strategical goals, and senior management support were mediated. Thus, it can be concluded that internal interaction is suggested as central for identifying needs and designing GLPS. Additionally, this thesis proposes that closer forms of interaction with technology providers in the design phase are important when implementing GLPs that include technology unfamiliar to the LSP.

\section{Operationalization of GLPs}

Once GLPs are designed, the phase that follows is the operationalization of the GLP. In the literature, it is suggested that the operationalization of a GLP should be implemented slowly, with initial tests that are upscaled to become fully operational (see e.g. Björklund \& Forslund, 2018). This is also evident in both the study on the consolidation center and the study on implementing alternative fuel. In the study on the consolidation center, it first only served a few types of products, before including additional types as time progressed, suggesting in line with da Mota Pedrosa (2012) that operationalization needs to be upscaled. In the study on implementing alternative fuel, the implementation of alternative fuel occurred stepwise. The haulage operator started by implementing diesel alternatives (e.g. RME or HVO100), which were both familiar to the drivers, but also had an established refueling infrastructure with familiar fuel providers. While the previous phase contains deeper forms of interaction that were important in the design of the GLPs, these interactions seem to become less important once the GLPs are being operationalized. This is most evident in the study on implementing alternative fuel, where the previous closer form of interaction between the haulage operator and the shippers becomes less collaborative, despite this form of interaction between shippers and LSPs being advocated to anticipate potential problems (da Mota Pedrosa, 2012). The haulage operator claimed that the shippers trust the haulage operator to perform according to the service levels promised and have little interest in spending resources on the interaction in addition to 


\section{Analysis and discussion}

procuring the shipping services. This suggests that external interaction becomes less collaborative in the operationalization phase.

Additionally, the previous close forms of interaction with the LBG fuel provider in the study on implementing alternative fuel also become less collaborative. Despite LBG fuel being a relatively new technology, the fuel provider showed no interest in gathering data, or exchanging knowledge and learnings regarding e.g. refueling processes or infrastructure once the GLP was operationalized. One note from the interactions explored in the study on implementing alternative fuel was that no interaction with the vehicle provider could be identified, further highlighting that no interaction to improve upon the technology or to aid the operationalization could be identified. This can be explained by the reduced interest from the fuel provider, that once the LSP and the haulage operator agreed upon purchasing that particular technology, no additional resources had to be invested in that interaction. Interaction, and especially closer forms of interaction, requires resources from both organizations, and can be costly to maintain (Vachon et al., 2009). However, despite the external interactions becoming less collaborative, the internal interaction between the LSP and the haulage operator remained as important and collaborative as in the previous phase. Additionally, in the operationalization phase, the need for interaction between the haulage operator and the drivers arose, as it suddenly become important to inform, and transfer knowledge regarding how the changes to the GLP affected daily operations. This suggests that internal interaction with a closer form of interaction is important in the operationalization of GLPS.

\section{Follow-up}

The last phase that concludes the implementation process of GLPs is the follow-up phase. Literature suggests that follow-up constitutes measuring the performance of e.g. an operationalized GLP, to ensure that effects match the desired outcomes (Barbosa \& Musetti, 2011). Additionally, measuring the performance of the GLP ensures that the identified need is fulfilled, as suggested by e.g. Ljungberg \& Larsson (2012). This was observed in the study on the consolidation center, where the motive behind the consolidation center was to improve the environmental performance of the municipalities. To properly perform the measurement of the consolidation center, all the affected organizations needed to either participate in the measurement, or to provide data for the measurement. This included interacting with a research institute, providing them with information and resources (e.g. time for interviews and compiling data). The interactions that occurred between the research institute and the other organizations in the study on the consolidation center all occurred during this last phase of the implementation process. The interactions were mostly arm's-length interactions, as communication was formal and infrequent, did not require any investments other than sharing resources in terms of time, and were not long-term or involving a high level of commitment. However, this interaction was necessary in order to perform the evaluation that established the success of the GLP, and that secured the continuous operation of the consolidation center.

It is suggested by e.g. Flint et al. (2005) that implementing innovative technology should be a cyclic process, where learnings from the implementation can be used to refine the innovation, thus eventually becoming an input for implementing other GLPs, but no such learnings or knowledge transfers were evident in the appended studies. As previously stated, no further interaction with the technology providers (e.g. vehicle or fuel provider) could be identified in the operationalization phase or after that phase. However, literature suggests that the follow-up phase can both be a performance measurement (e.g. Barbosa \& Musetti, 2011), but also a reflection on successes or failures in the implementation process (Björklund \& Forslund, 2018). These reflections can be used as learnings in other implementation processes, or as discussed 


\section{Analysis and discussion}

under the operationalization phase, as input for improving upon the technology or the GLP (see e.g. Flint et al., 2005). In the study on implementing alternative fuel, no interest in or interaction with the technology providers to share learnings or reflections could be identified. Interestingly, no internal interaction could be identified either, as the haulage operator stated that the LSP had no interest in receiving learnings that could be used to implement GLPs at other haulage operators. However, as the GLP was to implement alternative fuel and to form a fossil free fleet, no performance measurement was necessary for the study on implementing alternative fuel, as it was concluded that the fleet was fossil free once all vehicles were operationalized. This suggests that less collaborative forms of interaction with organizations affected by the GLP are required to measure the performance of implemented GLPS.

\subsubsection{How the phases characterize the interaction}

In the above reasoning, it was found that the different phases can require different forms of interaction, but also interaction between different organizations. How the different phases characterize the interactions are presented below in Table 5.3.

Table 5.3. Summary on how the phases characterize the interactions when implementing GLPs

\begin{tabular}{|c|c|c|c|}
\hline & $\begin{array}{l}\text { Identifying needs and } \\
\text { designing GLPs }\end{array}$ & Operationalization of GLPs & Follow-up \\
\hline $\begin{array}{l}\text { Internal } \\
\text { Interaction }\end{array}$ & $\begin{array}{l}\text { Internal interaction can } \\
\text { take various forms, } \\
\text { depending on the actors, } \\
\text { and is necessary to } \\
\text { identify the internal } \\
\text { motives, which are } \\
\text { required to identify } \\
\text { organizations that can be } \\
\text { interacted with. }\end{array}$ & $\begin{array}{l}\text { Internal interaction is } \\
\text { important to ensure a } \\
\text { successful implementation } \\
\text { and takes the form of more } \\
\text { arm's-length than } \\
\text { collaborative interaction. }\end{array}$ & $\begin{array}{l}\text { Internal interaction occurs } \\
\text { to ensure that all effects of } \\
\text { the implemented GLP are } \\
\text { captured. Typically, the } \\
\text { interactions are primarily } \\
\text { arm's-length, with the } \\
\text { most occurring action } \\
\text { being information sharing. }\end{array}$ \\
\hline $\begin{array}{l}\text { External } \\
\text { Interaction }\end{array}$ & $\begin{array}{l}\text { The external interactions } \\
\text { in this phase occur } \\
\text { primarily between } \\
\text { shippers and LSPs, and } \\
\text { LSPs and technology } \\
\text { providers. Typically, } \\
\text { they have a deeper form, } \\
\text { e.g. collaboration. }\end{array}$ & $\begin{array}{l}\text { External interaction becomes } \\
\text { less important in this phase. } \\
\text { Some examples of arm's- } \\
\text { length interaction are visible, } \\
\text { but in general, organizations } \\
\text { had an internal focus. }\end{array}$ & $\begin{array}{l}\text { The same characteristics } \\
\text { for internal interaction in } \\
\text { the follow-up phase apply } \\
\text { to the external interaction }\end{array}$ \\
\hline
\end{tabular}





\title{
6 Conclusions and future research
}

The final chapter, which concludes this licentiate thesis, is structured in three sections. The first section sets out to answer the research questions and the purpose of the licentiate thesis. This is followed by contributions and, lastly, future research.

\subsection{Answering research questions and purpose}

In the previous chapter, the findings in this thesis were presented as numerous statements. The statements are synthesized as conclusions for each research question. Finally, to fulfill the purpose of this thesis, the conclusions for each research question are wrapped up.

\subsubsection{Describing GLPs to include the need for interaction}

As a response to research question 1: How can GLPs be described to include the need for interaction? this thesis has identified two themes, which can add to the description of GLPs presented in the frame of reference (Chapter 2.1). The two themes are Motives and Organizational level of decision and impact and were found by analyzing the empirical studies to identify what drove LSPs to interact with other organizations when implementing GLPs.

\begin{abstract}
Motives
Motives to engage in greening logistics and implementing GLPs, are presented in the literature as consumer demands and to prepare for inevitable regulatory pressures (see e.g. Liimatainen et al., 2015), opportunities to secure competitive advantages (Sarkis, 2003; Kumar et al., 2012), or strong personal motives of key-individuals. This highlights that many organizations have motives for why LSPs should become greener and can be illustrated in the previous sentence by customers, shippers, authorities, LSPs themselves, and technology providers. This thesis adds to this description, as it has been identified that different organizations have different motives and interests in greening the logistics.
\end{abstract}

For different GLPs, different motives of different actors and organizations have been identified. For some GLPs, the central motives are to become greener without affecting current customer service levels in the logistics systems, while for other GLPs, for instance, Eco-driving, central motives are legislations. This showcases different motives, but that some motives are more dominant than others. For LSPs to implement a GLP that meets the expectations and corresponds to the motives of other actors and organizations, LSPs can interact with these actors and organizations. Additionally, as the organizations have motives as to why the LSP should implement GLPs, interaction can allow the LSP to access information, knowledge, or other resources held by other organizations to facilitate and mitigate the costs of implementing GLPs.

\section{Organizational level of decision and impact}

The implementation of GLPs requires decisions on different organizational levels (e.g. operational, tactical, strategical), and decisions on different levels will impact other levels (e.g. Aronsson \& Huge-Brodin, 2006). This is also supported in this thesis, where GLPs on higher organizational decision levels can lead to opportunities to implement GLPs on lower organizational decision levels. Additionally, this thesis also identifies that decisions on higher organizational levels can require decisions and implementation of GLPs on lower 


\section{Conclusions and future research}

organizational levels, which suggests that the higher organizational decision levels encompass the lower levels.

In addition to the previous statement, it has also been identified in this thesis that implementing GLPs on lower organizational levels can lead to opportunities to implement GLPs on any of the organizational levels above. This expands prior knowledge, with that decisions on any organizational level can enable decisions to implement GLPs on any other organizational decision level.

The reason why GLPs can enable or require the implementation of other GLPs on additional organizational decision levels is the interaction that occurs to implement GLPs. The interaction that occurs when implementing one GLP can be used to implement other GLPs, without additional interaction. For some organizations, the implementation of GLPs requires the involvement of other organizations and actors, which widens the scope of GLPs because it requires the involvement of other organizations to be implemented. Thus, while a GLP might be considered to impact an operational decision level, organizations must interact with other organizations that correspond to interacting on a higher decision level than the GLP is implemented on.

\subsubsection{The forms of interactions that occur when implementing GLPs.}

As a response to research question 2: What forms of interactions can occur when implementing green logistics practices? interactions have been explored to identify which organizations or actors interact, what the interactions consist of, and what form of interaction occurs.

The findings suggest that closer forms of interaction between Shippers and LSPs are central for the implementation of GLPs. Additionally, this thesis identifies that organizations other than the Shippers, are important for the LSP to interact with, including both more collaborative forms of interaction and with more arm's-length forms of interaction. This finding is in line with the need of broadening the empirical scope as identified in Paper I. Interaction can have different purposes, and in this thesis, interacting to acquire resources from other organizations has been identified as central. In general, information sharing has been identified as the main source of acquiring additional information, knowledge, or resources within all identified interactions. As information is mediated through communication with other organizations, functioning communication is vital when interacting. Additionally, findings suggest that LSPs need to absorb knowledge from other organizations on their views and understandings of the logistics system to implement GLPs.

In addition to identifying the need to interact externally with other organizations to implement GLPs, this thesis identifies internal interaction as important. Internal interaction enables organizations to implement GLPs, but also to form the external interactions that are necessary. Internal interaction, using a more collaborative form of interaction, was identified as important for the implementation of GLPs, which can be exemplified through top-management support or interrelating the effects of the GLPs with functions other than logistics. From the systematic literature review in Paper I, it was suggested that different actors within organizations can have different perspectives and experiences of interaction, which this thesis found was true. These different experiences of internal actors, in turn, formed the external interactions with other organizations. 


\subsubsection{The characteristics of interaction in different phases of implementing GLPs}

As a response to research question 3: What characterizes the interactions that occur in the different phases of implementing GLPs? interactions explored in research question 2 were explored further to identify different characteristics of the interactions in the implementation process. Three phases were identified: identifying needs and designing GLPS, Operationalization of GLPs, and follow-up. The interaction that occurs when implementing GLPs is mainly characterized in the first phase as a closer form of internal interaction between actors and closer forms of external interaction between LSPs and both Shippers and technology providers. The internal interaction is of importance to align the motives to why the GLP should be implemented and identify what information, resources, and knowledge are held within the organization. The external interactions are important to design a GLP that will not have opposed the promises to the shippers and their customers or their needs and to gain an understanding of the technology that the GLP might require.

The interactions that occur in the second phase are mainly characterized as remaining as a closer form of internal interaction between actors within organizations. This is of importance to ensure a successful operationalization and that all actors are aware of the changes that implementing a GLP might require. The external interactions become more arm's-length focused or even cease to exist in the operationalization phase. This is suggested as the result of interaction going both ways and that organizations such as technology providers or Shippers no longer have anything more to offer in the interaction or to gain from the interaction. For instance, once the technology has been chosen and procured, no need to interact with the technology providers exist.

In the third phase, the interactions are characterized by mostly arm's-length external interactions but appearing between several organizations. This is suggested as the result of the importance to consider the effects of GLPs on other organizations and actors, to measure the performance of GLPs. Since GLPs are designed and implemented with respect to other organizations' operations and motives, it is also important to consider these organizations in the evaluation of the GLP. However, if the GLP does not require any performance measurement to evaluate the GLP, no interaction can be identified in the last phase. This includes both external and internal interactions.

\subsubsection{Interaction to facilitate LSPs to implement GLPs}

To answer the purpose: Explore how supply chain interaction can facilitate logistics service providers to implement green logistics practices, the following are synthesized from each research question. First, interaction is important when implementing GLPs. This is illustrated by both being able to connect GLPs to interaction but also showcased by interaction's ability to allow organizations to acquire information, knowledge, or resources from other organizations, items that would have been costly to acquire in other ways. This is also why it can be of importance to consider the interaction when discussing the different organizational decision levels that different GLPs will impact. For some organizations, seemingly operational GLPs can be experienced as tactical or even strategic decisions, as the interactions that occur when implementing the GLP correspond to decisions on a higher organizational level.

Interaction between different organizations is important, but internal interaction within LSPs and external interaction between shippers and LSPs appears vital to implement GLPs. Topmanagement support, and allocation of resources, gathering information or knowledge, are all 


\section{Conclusions and future research}

mediated through internal interaction, which in turn identifies the needs and motives to implement GLPs and to become greener. Internal interaction is also important for the operationalization of GLPs, as they will require changes in everyday operations. External interaction between shippers and LSPs is important so that GLPs are designed not to affect the customer service levels promised from the LSP to the shippers, and by extension, to the shippers' customers. This interaction also enables LSPs and Shippers to share resources, which can be expressed as increased freight costs or accepting decreased service levels. This thesis also identifies that the external interaction between Shippers and LSP does not necessarily have to be a deeper form of interactions (e.g., collaboration) but can vary with the implementation process.

This thesis proposes that different forms of interactions with different organizations and in different phases of implementing GLPs facilitate the implementation, as deeper forms of interaction can be costly to withhold. In the thesis, it has been illustrated that the different phases of implementation also require different forms of interaction with different organizations or actors, depending on the phase of implementation. Thus, by interacting with various forms of interaction, LSPs can manage their resources, information, or knowledge, put into the interactions, in a more efficient way. This is also supported by findings that indicate that interaction for implementing a GLP can facilitate the implementation of other GLPs, as organizations might have acquired resources, information, or knowledge, that are sufficient for additional GLPs. Thus, interaction can facilitate the implementation of GLPs in different ways, either by facilitating the implementation of one GLP or that the interaction for implementing a GLP can facilitate the implementation of additional GLPs.

\subsection{Contributions}

This licentiate thesis provides contributions to both research and practice. These are expanded upon respectively, below.

\subsubsection{Contributions to research}

This thesis contributes to research, mainly to green logistics literature, in different ways. First, with the focus on LSPs, this thesis addresses the findings from Paper I, that more focus needs to be directed toward LSPs, as they correspond to a large share of the negative environmental impact. Despite their important role in the greening of logistics, LSPs have been given little interest in the field of sustainable supply chains. With its focus on interaction, this thesis addresses that the term collaboration is overused or used interchangeably for any form of interaction (Soosay \& Hyland, 2015) by examining the different forms of interaction that occur when implementing GLPs. Indeed, collaboration exists and is important, but often in distinct phases of the implementation process and between certain organizations. Additionally, this thesis has identified the need to have different forms of interactions between organizations other than shippers and LSPs, which helps identify what types of organizations to explore when calling for a wider holistic perspective on the greening of logistics (e.g. as in Paper I). Also, one of the main contributions of this thesis is the differentiation of external and internal interaction, which can add to the dimension of having a wider perspective.

Second, this thesis has further added to the literature that investigates and explores GLPs. Within the field of green logistics, it exists different ways to describe and present GLPs. With an interaction perspective, this thesis has presented two themes of how GLPs can be described 


\section{Conclusions and future research}

to include the need for interaction. The themes motives and organizational level of decision and impact help with identifying the need for interaction when implementing GLPs. Additionally, this thesis also abstains from discussing the actual costs of implementing GLPs and instead refers to the cost of implementing GLPs as resources, information, and knowledge. This exemplifies that costs can be more than just financial means and can be the reason why some organizations engage in the greening of logistics by implementing GLPs that can be costly, whilst others do not. In a low-marginal industry in which LSPs operate (Piecyk \& Björklund, 2015), expressing costs as something else than financial means can be investigated to explore the phenomena of why some LSPs chooses to become greener, whilst others do not.

Third, this thesis investigates the implementation process of implementing GLPs. The process of implementing logistics innovation (Flint et al., 2005) or the implementation of sustainable logistics innovation (Björklund \& Forslund, 2018) has been scarcely investigated throughout the field of logistics, and in particular the field of green logistics. Implementing GLPs can require the adaptation of new processes or the implementation of new technology, and by focusing the process, that is, the implementation of GLPs, increased understanding of success factors and the barriers of implementing GLPs can be gained. This thesis has empirically investigated the process that is the implementation of GLPs and provides a suggestion for how the process can be classified into different phases from the perspective of interaction.

Lastly, as no uniform generalized definition of GLPs exists, it is important to look at GLPs from all perspectives. Once GLPs have been explored from every possible perspective, a generalized definition can be presented. This thesis adds to research on GLPs by exploring GLPs from one perspective.

\subsubsection{Contributions to practice}

The findings in this thesis can contribute to practice by highlighting that interaction enables LSPs and other organizations such as transport buyers or authorities to consider other aspects than the required financial means the implementation of a GLP might require. It showcases that internal interaction can help organizations identify what information, resources, and knowledge they possess, which can be used to implement GLPs. Additional information, resources, or knowledge required can be gathered by interacting externally or internally with organizations or actors that hold the desired items. Naturally, interactions require inputs, but these inputs can be something that the organizations possess and do not necessarily have to be financial means. In other words, the findings show that by including other organizations or actors in the implementation process through interaction, the process of implementing GLPs would be shared by several organizations, instead of the LSP being alone in the process.

The main points of departure for this licentiate thesis were to find ways that could facilitate the implementation of GLPs, thus greening the logistics. It has been illustrated how interaction can facilitate the implementation of GLPs through sharing resources, information, and knowledge. Many organizations have motives as to why, e.g. LSPs should implement GLPs and offer green services, and by extension are also willing to participate in the implementation process. By interacting with these organizations, LSPs can gather information, resources, or knowledge, which they would have been required to purchase or acquire on their own. Thus, the findings and illustrations within this thesis, can help other organizations, to identify what organizations or actors they can include to implement GLPs. 


\section{Conclusions and future research}

\subsection{Future research}

As for all research, interspersing findings open for additional studies to either expand upon current research or explore what could not be investigated in the scope of this thesis. Four areas that have been identified for future research are expanded upon below.

\subsubsection{Beyond a Swedish context}

In this thesis, all the explored GLPs and interactions were in a Swedish context. Notably, some of the motives behind implementing GLPs, in particular for eco-driving, were legislations that might not be present in other contexts. Also, other motives be connected to this context, as available technology, infrastructure, or subsidies differ with geographical areas, can be derived from the studies in the Swedish context. Thus, it would be interesting to do similar studies in other geographical contexts to see if there are similarities or differences compared to the studies within this thesis.

\subsubsection{The benefits of interacting}

In this thesis, one of the focuses of interaction has been to explore the resources, information or knowledge required when implementing GLPs, and not on the benefits that the implementation can lead to. For instance, the implementation of a GLP can lead to different benefits for different organizations and actors, which can also be mediated through interaction. These benefits can be seen as additional motives for participating in the implementation of GLPs, and therefore should be investigated further. Thus, the total benefits in the logistics system can be compared to the total costs (as a collective term for resources, information, or knowledge) or efforts of the organizations participating in the implementation.

\subsubsection{Learnings from the implementation process}

In this thesis, the organizations did not use any learnings from the implementation process or the successful implementations in other contexts. This can be the result of insufficient studies of the follow-up phase. Additional studies on the follow-up phase could give insights on how organizations should utilize these learnings and insights, either by sharing them with other organizations (calling for additional interactions) or in larger organizations, use the learnings when implementing GLPs in other functions, which could suggest that interaction can be used to implement other green practices than logistics.

\subsubsection{Longitudinal studies on the interaction}

In this thesis, the process of implementation and the different GLPs investigated are so from the perspective of different studies. None of the studies follows the implementation of GLPs through all different phases of implementation. Therefore, suggestions for future research are to study the implementation of GLPs longitudinally to gain a better understanding of how interactions are formed and changed during the implementation process. Additionally, this would increase the knowledge of how organizations identify GLPs and design and operationalize efficient and suitable GLPs for their purposes. This would also require studying organizations in the follow-up phase, where GLPs are concluded as successful solutions to external or internal needs. 


\section{References}

Allen, J., Browne, M., Woodburn, A. \& Leonardi, J., (2012). "The role of urban consolidation centres in sustainable freight transport", Transport Reviews, 32, 473-490.

Anderhofstadt, B. \& Spinler, S., (2019). "Factors affecting the purchasing decision and operation of alternative fuel-powered heavy-duty trucks in Germany-A Delphi study", Transportation Research Part D: Transport and Environment, 73, 87-107.

Arbnor, I. \& Bjerke, B., (1994). Företagsekonomisk metodlära, 2., [omarb. och utök.] uppl. ed. Studentlitteratur.

Aronsson, H. \& Huge-Brodin, M., (2006). "The environmental impact of changing logistics structures", The international journal of logistics management.

Barbosa, D.H. \& Musetti, M.A., (2011). "The use of performance measurement system in logistics change process: Proposal of a guide", International Journal of Productivity and Performance Management, 60, 339-359.

Barkenbus, J.N., (2010). "Eco-driving: An overlooked climate change initiative", Energy Policy, 38, 762-769.

Bask, A. \& Rajahonka, M., (2017). "The role of environmental sustainability in the freight transport mode choice: A systematic literature review with focus on the EU", International Journal of Physical Distribution \& Logistics Management, 47, 560-602.

Bask, A., Rajahonka, M., Laari, S., Solakivi, T., Töyli, J. \& Ojala, L., (2018). "Environmental sustainability in shipper-LSP relationships", Journal of Cleaner Production, 172, 2986-2998.

Berglund, M., Van Laarhoven, P., Sharman, G. \& Wandel, S., (1999). "Third-Party Logistics: Is There a Future?", The International Journal of Logistics Management, 10, 59-70.

Björklund, M., Abrahamsson, M. \& Johansson, H., (2017). "Critical factors for viable business models for urban consolidation centres", Research in Transportation Economics, 64, 36-47.

Björklund, M. \& Forslund, H., (2018). "Exploring the sustainable logistics innovation process", Industrial management + data systems, 118, 204-217.

Björklund, M., Forslund, H. \& Isaksson, M.P., (2016). "Exploring logistics-related environmental sustainability in large retailers", International Journal of Retail \& Distribution Management.

Björklund, M. \& Johansson, H., (2018). "Urban consolidation centre-a literature review, categorisation, and a future research agenda", International Journal of Physical Distribution \& Logistics Management, 48, 745-764.

Bowersox, D.J., (1992). Logistical excellence : it's not business as usual Digital Press.

Brandenburg, M., Gruchmann, T. \& Oelze, N., (2019). "Sustainable supply chain management-A conceptual framework and future research perspectives", Sustainability, 11, 7239.

Bryman, A. \& Bell, E., (2015). Business research methods Oxford University Press, USA.

Busse, C. \& Marcus Wallenburg, C., (2011). "Innovation management of logistics service providers: Foundations, review, and research agenda", International Journal of Physical Distribution \& Logistics Management, 41, 187-218.

Cao, M. \& Zhang, Q., (2011). "Supply chain collaboration: Impact on collaborative advantage and firm performance", Journal of Operations Management, 29, 163-180.

Carter, C.R. \& Rogers, D.S., (2008). "A framework of sustainable supply chain management: moving toward new theory", International journal of physical distribution \& logistics management, 38, 360-387. 
Centobelli, P., Cerchione, R. \& Esposito, E., (2017). "Environmental sustainability in the service industry of transportation and logistics service providers: Systematic literature review and research directions", Transportation Research Part D: Transport and Environment, 53, 454-470.

Christopher, M., (2005). Logistics and supply chain management: creating value-adding networks Pearson education.

Chu, Z., Wang, L. \& Lai, F., (2019). "Customer pressure and green innovations at third party logistics providers in China: The moderation effect of organizational culture", The International Journal of Logistics Management, 30, 57-75.

Colicchia, C., Marchet, G., Melacini, M. \& Perotti, S., (2013). "Building environmental sustainability: empirical evidence from Logistics Service Providers", Journal of Cleaner Production, 59, 197-209.

Cooper, M.C. \& Gardner, J.T., (1993). "Building good business relationships: more than just partnering or strategic alliances?", International Journal of Physical Distribution \& Logistics Management.

Da Mota Pedrosa, A., (2012). "Customer Integration during Innovation Development: An Exploratory Study in the Logistics Service Industry", Creativity and Innovation Management, 21, 263-276.

Da Mota Pedrosa, A., Blazevic, V. \& Jasmand, C., (2015). "Logistics innovation development: a micro-level perspective", International Journal of Physical Distribution \& Logistics Management, 45, 313-332.

DB Schenker, (2020). Hållbarhetsredovisning 2019: https://www.dbschenker.com/resource/blob/664126/ed556a8900efdfa9c9ce576a02a42 479/db-schenker-h\%C3\%A5llbarhetsredovisning-2019-data.pdf.

DHL, (2020). 2019 Sustainanbility Report: https://www.dhl.com/content/dam/dhl/global/core/documents/pdf/sustainabilityreport.pdf.

Dubois, A. \& Gadde, L.-E., (2014). "“Systematic combining"—A decade later", Journal of Business Research, 67, 1277-1284.

Dyer, J.H. \& Singh, H., (1998). "The relational view: Cooperative strategy and sources of interorganizational competitive advantage", Academy of management review, 23, 660679.

Eng-Larsson, F. \& Norrman, A., (2014). "Modal shift for greener logistics- exploring the role of the contract", International Journal of Physical Distribution \& Logistics Management.

Eng-Larsson, F. \& Kohn, C., (2012). "Modal shift for greener logistics - the shipper's perspective", International Journal of Physical Distribution \& Logistics Management, 42, 36-59.

Evangelista, P., (2014). "Environmental sustainability practices in the transport and logistics service industry: An exploratory case study investigation", Research in Transportation Business \& Management, 12, 63-72.

Evangelista, P., Santoro, L. \& Thomas, A., (2018). "Environmental sustainability in thirdparty logistics service providers: A systematic literature review from 2000-2016", Sustainability, 10, 1627.

Flint, D.J., Larsson, E., Gammelgaard, B. \& Mentzer, J.T., (2005). "Logistics innovation: a customer value-oriented social process", Journal of business logistics, 26, 113-147.

Flynn, B.B., Huo, B. \& Zhao, X., (2010). "The impact of supply chain integration on performance: A contingency and configuration approach", Journal of Operations Management, 28, 58-71. 
Goes, G., Bandeira, R., Gonçalves, D., De Almeida D'agosto, M. \& Oliveira, C., (2020). "The effect of eco-driving initiatives toward sustainable urban waste collection", International Journal of Sustainable Transportation, 14, 569-578.

González-Benito, J. \& González-Benito, Ó., (2006). "The role of stakeholder pressure and managerial values in the implementation of environmental logistics practices", International Journal of Production Research, 44, 1353-1373.

H\&M, (2020). Sustainability Perforamnce Report 2019: https://hmgroup.com/wpcontent/uploads/2020/10/HM-Group-Sustainability-Performance-Report-2019.pdf.

Holmberg, K., Andersson, P., Nylund, N.-O., Mäkelä, K. \& Erdemir, A., (2014). "Global energy consumption due to friction in trucks and buses", Tribology International, 78, 94-114.

Huang, Y., Ng, E.C.Y., Zhou, J.L., Surawski, N.C., Chan, E.F.C. \& Hong, G., (2018). "Ecodriving technology for sustainable road transport: A review", Renewable and Sustainable Energy Reviews, 93, 596-609.

IEA, (2018). Global CO2 emissions by sector, 2018 [online]. IEI, Paris. Available from: https://www.iea.org/data-and-statistics/charts/global-co2-emissions-by-sector-2018 [Accessed Nov 19 2020].

International Transport Forum, (2019). ITF Transport Outlook 2019.

Jazairy, A., (2020a). "Aligning the purchase of green logistics practices between shippers and logistics service providers", Transportation Research Part D: Transport and Environment, 82, 102305.

Jazairy, A., (2020b). Engaging in green logistics: An eye on shippers, logistics service providers, and their interactions. Doctoral thesis, comprehensive summary. KTH Royal Institute of Technology.

Jazairy, A. \& Von Haartman, R., (2020). "Measuring the gaps between shippers and logistics service providers on green logistics throughout the logistics purchasing process", International Journal of Physical Distribution \& Logistics Management.

Johansson, H., (2020). Customer Benefits in City Logistics : Towards Viable Urban Consolidation Centres. Doctoral thesis, comprehensive summary. Linköping University Electronic Press.

Kohn, C. \& Huge-Brodin, M., (2008). "Centralised distribution systems and the environment: how increased transport work can decrease the environmental impact of logistics", International Journal of Logistics Research and Applications, 11, 229-245.

Krause, D.R., Vachon, S. \& Klassen, R.D., (2009). "Special topic forum on sustainable supply chain management: introduction and reflections on the role of purchasing management", Journal of Supply Chain Management, 45, 18-25.

Kumar, S., Teichman, S. \& Timpernagel, T., (2012). "A green supply chain is a requirement for profitability", International Journal of Production Research, 50, 1278-1296.

Lammgård, C., (2012). "Intermodal train services: A business challenge and a measure for decarbonisation for logistics service providers", Research in Transportation Business \& Management, 5, 48-56.

Lee, S.-Y., Klassen, R.D., Furlan, A. \& Vinelli, A., (2014). "The green bullwhip effect: Transferring environmental requirements along a supply chain", International Journal of Production Economics, 156, 39-51.

Leonardi, J., Cullinane, S. \& Edwards, J., (2015). Alternative fuels and freight vehicles: Status, costs and benefits, and growth. In A. Mckinnon, M. Browne, A. Whiteing \& M. Piecyk (eds.) Green logistics: Improving the environmental sustainability of logistics. Kogan Page Publishers. 
Liimatainen, H., Hovi, I.B., Arvidsson, N. \& Nykänen, L., (2015). "Driving forces of road freight CO2 in 2030", International Journal of Physical Distribution \& Logistics Management.

Ljungberg, A. \& Larsson, E., (2012). Processbaserad verksamhetsutveckling : [varför - vad hur?], 2., kraftigt omarb. och utök. uppl. ed. Studentlitteratur.

Madhusudhanan, A.K., Ainalis, D., Na, X., Garcia, I.V., Sutcliffe, M. \& Cebon, D., (2021). "Effects of semi-trailer modifications on HGV fuel consumption", Transportation Research Part D: Transport and Environment, 92, 102717.

Martinsen, U. \& Huge-Brodin, M., (2014). "Environmental practices as offerings and requirements on the logistics market", Logistics Research, 7, 115.

Mckinnon, A., (2010). "Green logistics: the carbon agenda", Electronic Scientific Journal of Logistics, 6.

Mckinnon, A., (2015a). Enviromental Sustainability: A new priority for logistics managers. In A. Mckinnon, M. Browne, A. Whiteing \& M. Piecyk (eds.) Green logistics: Improving the environmental sustainability of logistics. Kogan Page Publishers.

Mckinnon, A., (2015b). Opportunities for improving vehicle utilization. In A. Mckinnon, M. Browne, A. Whiteing \& M. Piecyk (eds.) Green logistics: Improving the environmental sustainability of logistics. Kogan Page Publishers.

Murfield, M.L. \& Tate, W.L., (2017). "Buyer and supplier perspectives on environmental initiatives: potential implications for supply chain relationships", The International Journal of Logistics Management, 28, 1319-1350.

Patel, R. \& Davidson, B., (2011). Forskningsmetodikens grunder : att planera, genomföra och rapportera en undersökning Studentlitteratur: Lund.

Perotti, S., Zorzini, M., Cagno, E. \& Micheli, G.J., (2012). "Green supply chain practices and company performance: the case of 3PLs in Italy", International Journal of Physical Distribution \& Logistics Management, 42, 640-672.

Persdotter Isaksson, M., Hulthén, H. \& Forslund, H., (2019). "Environmentally Sustainable Logistics Performance Management Process Integration between Buyers and 3PLs", Sustainability, 11, 3061.

Piecyk, M.I. \& Björklund, M., (2015). "Logistics service providers and corporate social responsibility: sustainability reporting in the logistics industry", International Journal of Physical Distribution \& Logistics Management.

Rogerson, S. \& Santén, V., (2017). "Shippers' opportunities to increase load factor: managing imbalances between required and available capacity", International Journal of Logistics Research and Applications, 20, 581-603.

Rogerson, S., Santén, V., Svanberg, M., Williamsson, J. \& Woxenius, J., (2020). "Modal shift to inland waterways: dealing with barriers in two Swedish cases", International Journal of Logistics Research and Applications, 23, 195-210.

Sarkis, J., (2003). "A strategic decision framework for green supply chain management", Journal of cleaner production, 11, 397-409.

Sharma, S. \& Choudhury, A.G., (2014). "A qualitative study on evolution of relationships between third-party logistics providers and customers into strategic alliances", Strategic Outsourcing: An International Journal.

Soosay, C.A. \& Hyland, P., (2015). "A decade of supply chain collaboration and directions for future research", Supply Chain Management: An International Journal, 20, 613630.

Soosay, C.A., Hyland, P.W. \& Ferrer, M., (2008). "Supply chain collaboration: capabilities for continuous innovation", Supply Chain Management: An International Journal, 13, 160-169. 
Spekman, R.E., Kamauff, J.W. \& Myhr, N., (1998). "An empirical investigation into supply chain management: a perspective on partnerships", Supply Chain Management: An International Journal.

Stank, T.P., Keller, S.B. \& Daugherty, P.J., (2001). "SUPPLY CHAIN COLLABORATION AND LOGISTICAL SERVICE PERFORMANCE", Journal of Business Logistics, 22, 29-48.

Touboulic, A. \& Walker, H., (2015a). "Love me, love me not: A nuanced view on collaboration in sustainable supply chains", Journal of Purchasing and Supply Management, 21, 178-191.

Touboulic, A. \& Walker, H., (2015b). "Theories in sustainable supply chain management: a structured literature review", International Journal of Physical Distribution \& Logistics Management.

Tranfield, D., Denyer, D. \& Smart, P., (2003). "Towards a methodology for developing evidence-informed management knowledge by means of systematic review", British journal of management, 14, 207-222.

Vachon, S., Halley, A. \& Beaulieu, M., (2009). "Aligning competitive priorities in the supply chain: the role of interactions with suppliers", International Journal of Operations \&amp; Production Management, 29, 322-340.

Vachon, S. \& Klassen, R.D., (2008). "Environmental management and manufacturing performance: The role of collaboration in the supply chain", International Journal of Production Economics, 111, 299-315.

Wagner, S.M., (2008). "Innovation management in the German transportation industry", Journal of Business Logistics, 29, 215-231.

Walker, H., Di Sisto, L. \& Mcbain, D., (2008). "Drivers and barriers to environmental supply chain management practices: Lessons from the public and private sectors", Journal of Purchasing and Supply Management, 14, 69-85.

Wolf, C. \& Seuring, S., (2010). "Environmental impacts as buying criteria for third party logistical services", International Journal of Physical Distribution \& Logistics Management, 40, 84-102.

Wu, H.J. \& Dunn, S.C., (1995). "Environmentally responsible logistics systems", International journal of physical distribution \& logistics management.

Yin, R.K., (2014). Case study research : design and methods, 5. ed. ed. SAGE. 


\section{Papers}

The papers associated with this thesis have been removed for copyright reasons. For more details about these see:

http://urn.kb.se/resolve?urn=urn:nbn:se:liu:diva-175574 


\section{FACULTY OF SCIENCE AND ENGINEERING}

Linköping Studies in Science and Technology, Licentiate Thesis No. 1909, 2021 Department of Management and Engineering

Linköping University

SE-581 83 Linköping, Sweden

www.liu.se

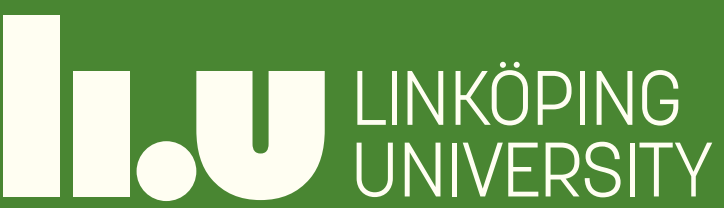

